Manuscript Number: CACE-D-15-00324R1

Title: Optimal Integration of Third-Parties in a Coordinated Supply Chain Management Environment

Article Type: Full Length Paper

Section/Category: Enterprise-wide management and technology-driven policy making

Keywords: Coordinated Management, 3rd Party, Supply Chain Planning, Pricing Models, Demand Elasticity.

Corresponding Author: Dr. Antonio Espuña, Doctor

Corresponding Author's Institution: Universidad Politecnica de Catalunya

First Author: Kefah Hjaila

Order of Authors: Kefah Hjaila; José M. Laínez-Aguirre, Dr.; Miguel A. Zamarripa, Dr.; Luis Puigjaner ; Antonio Espuña

Abstract: A generic tactical model is developed considering the third parties price policies for the optimization of coordinated and centralized multi-product supply Chains (SCs). To allow more realistic assessment of these policies in each marketing situation, different price approximation models to estimate these policies are proposed, based on the demand elasticity theory, resulting in different model implementations (LP, NLP, and MINLP). The consequences of using the proposed models on the SCs coordination, regarding not only their practical impact on the tactical decisions, but also the additional mathematical difficulties to be solved, are verified through a case study in which the coordination of a production-distribution SC and its energy generation SC is analyzed. The results show how the selection of the price approximation model affects the tactical decisions. The average price approximation leads to the worst decisions with a significant difference in the real total cost comparing with the best piecewise approximation. 
- Different approximation models are proposed to estimate $3^{\text {rd }}$ parties price policies.

- The pricing approximation lead to mathematical complexities (LP, NLP and MINLP).

- The selection of a pricing model significantly affects the tactical decisions.

- The average price approximation leads to the worst real decisions. 


\title{
Optimal Integration of Third-Parties in a Coordinated Supply Chain Management Environment
}

\author{
Kefah Hjaila1' José M. Laínez-Aguirre ${ }^{2}$, Miguel Zamarripa ${ }^{1}$, Luis Puigjaner ${ }^{1}$ and Antonio \\ Espuña ${ }^{*}$ \\ ${ }^{1}$ Chemical Engineering Department, Universitat Politècnica de Catalunya, ETSEIB., Av. Diagonal 647, 08028 \\ Barcelona, Spain. \\ ${ }^{2}$ Department of Industrial and Systems Engineering, University at Buffalo, NY, United States. \\ *corresponding author: antonio.espuna@upc.edu
}

\begin{abstract}
A generic tactical model is developed considering the third parties price policies for the optimization of coordinated and centralized multi-product Supply Chains (SCs). To allow more realistic assessment of these policies in each marketing situation, different price approximation models to estimate these policies are proposed, based on the demand elasticity theory, resulting in different model implementations (LP, NLP, and MINLP). The consequences of using the proposed models on the SCs coordination, regarding not only their practical impact on the tactical decisions, but also the additional mathematical difficulties to be solved, are verified through a case study in which the coordination of a production-distribution SC and its energy generation SC is analyzed. The results show how the selection of the price approximation model affects the tactical decisions. The average price approximation leads to the worst decisions with a significant difference in the real total cost comparing with the best piecewise approximation.
\end{abstract}

Keywords: Coordinated Management, 3 ${ }^{\text {rd }}$ Party, Supply Chain Planning, Pricing Models, Demand Elasticity.

\section{INTRODUCTION}

A Supply Chain (SC) is constituted by a set of echelons: suppliers, storage facilities, production plants, distribution centers, and markets (retailers), which are located in different geographic sites, linked together through distribution systems, and interacting with third parties. When all these echelons belong to one single organization, the SC may be managed in a "centralized" way, and some coordination is necessary to harmonize the resources flow among these echelons, and their third parties. Supply Chain Management (SCM) aims to optimize the performance of a SC (e.g., its financial revenues), establishing how and when: the resources flow between echelons, raw materials should be transformed into intermediate/final products, and finally the final products should be distributed to customers.

In recent years, the competitiveness among global SCs has grown resulting in new challenges in the area of Process System Engineering (PSE) which include an enhanced management of the chemical supply chain. In this sense, the European Petrochemical Association (EPCA) as well as the European Chemicals Industry Council (CEFIC) have suggested that improving SCM at all levels will increase business competitiveness (McKinnon, 2004). Among the SCM developments that have been proposed to reduce the SC cost and to increase profitability are: effective distribution of resources over the SC network (Shah, 
2005), collaboration and coordination between SCs (Papageorgiou, 2009; Hjaila et al., 2015), cooperation and competitiveness (Zamarripa et al., 2013, 2014), robustness (Laínez-Aguirre et al., 2015), and incorporation of demand management and corporate financial decisions (Shapiro, 2004; Grossmann, 2005).

These issues can be addressed at different hierarchical decision levels, through designing the SC (Laínez et al., 2009; Mellichamp, 2013), providing an improved master plan (Amaro and Barbosa-Póvoa, 2009; Zeballos et al., 2012; Cao et al., 2013; Zeballos et al., 2014; Zamarripa et al., 2014; Hjaila et al., 2014,2015), and/or controlling the involved operations (Guillén et al., 2006; Sung and Maravelias, 2007; Shah and Ierapetritou, 2012), as will be discussed later.

This work makes a specific emphasis on the tactical decision-making level of centralized SCs. More specifically, efficient SCs Coordination (SCsCo) that deals with all echelons (i.e., supplier's echelons, production echelons) as full SCs, taking into account the decisions of the third parties which becomes a challenging problem as enterprises seek competitive performance.

SCsCo has been studied from different perspectives; one of the more appealing approaches intends to integrate different hierarchical SCM decision-making levels within a single SC model. For instance, Laínez et al. (2009) integrate the strategic and tactical levels within a single flexible model, representing the manufacturing process recipe, and considering all possible feasible links and material flows. Several ways to address this management integration problem at the lower levels of the decision-making hierarchy have been proposed, as in the work by Guillén et al. (2006), where an enterprise budgeting approach following a cash flow formulation for a multi-product SC is proposed. Sung and Maravelias (2007) develop an integration approach for multiproduct process networks, where the operational model is developed and solved off-line to obtain convex approximation functions of the production costs and production levels. Shah and Ierapetritou (2012) extend the single site formulation proposed by $\mathrm{Li}$ and Ierapetritou (2010) for multi-site multiproduct multi-purpose batch plants. But neither these works, nor any other work addressing the integration between the different SC hierarchical levels, consider the coordination among different echelons (with their respective SCs) of a global SC structure at the same level (i.e., tactical level) taking into consideration the main objectives of all these participating echelons/SCs, including the decisions related to third parties.

The need of effective SCsCo also appears when several SCs with different policies/objectives work together, such as the case of closed-loop SCs, where the coordination between forward and reverse flows is required on one side, and between their respective SCs and the third parties on the other side. In closed-loop SCM, this coordination should be introduced into the model formulation by considering the recovery processes and the reuse of the final products, where the final demand is satisfied by both new and remanufactured products. In this way, Amaro and Barbosa-Póvoa (2009) develop a closed-loop tactical model considering that the retail price and demand of final products are uncertain; however, the final product price is considered as uncertain parameter independently from the quantity demanded along the planning time horizon. The closed-loop formulations are also applied to 
SCM integration models, such as in Zeballos et al. (2014), who propose an integrated strategic and tactical multi-period multi-product closed-loop model for a 10-layer SC network (forward and reverse flows). Notwithstanding, the aforementioned closed-loop models aim to optimize the global objective resulting from the coordination between the direct and reverse flows, disregarding the individual objectives of the participating echelons SCs and their third parties, which may lead to inadequate decision-making.

The coexistence and coordination of different individual objectives have been analyzed using approaches based on the Game Theory, such as in the work of Hjaila et al. (2015), who represent the individual objectives as non-cooperative non-zero-sum Stackelberg game considering the risk associated with the uncertain nature of the third parties. Yue and You (2014) develop an integrated strategic and tactical bi-level model for the optimization of non-cooperative multi-echelon SC considering the objectives of both customers and manufacturers (highest profit) under the leading role of the manufacturer; however, their approach considers that the manufacturer echelon dominates the decision-making process, disregarding the individual objectives of the suppliers' echelon SC. Along the same line, Cao et al. (2013) propose a coordination mechanism considering the individual goals of the participating actors through "revenue sharing" based on Stackelberg game for a SC network of one manufacturer and many retailers considering a penalty cost when production cost and demand are disrupted; to solve the competence among different retailers, the model is solved as a game under the leading role of the manufacturer, while the retailers act as followers: the manufacturer offers the retailers a set of contracts (sale prices and revenue share), and each retailer chooses its preferred contract. Garcia-Herreros et al. (2015) coordinates multiple independent markets through bi-level optimization, in which the upper level problem maximizes the revenue of the producers, while the lower level problem minimizes the market expenses.

However, none of these models considers the financial policies of the suppliers' SCs and their third parties when providing the leader decision-making, which may affect the outcome of the game. In summary, most of the previous tactical SCM approaches consider that all the echelons of the SC share a common global objective (centralized), while the detailed behaviors of the third parties participating in the resources and information flows of the SC of interest, with their own objectives, are usually neglected, or reduced to a single parameter in the optimization models. Few others explicitly consider these third parties' objectives, but without enabling any degree of freedom in their modeled behavior to represent their capacity and consequently to control their own performance. But, in practice, the SC network will seek its own objectives based on its independent characteristics and economic incentives, disregarding the impact of the third parties especially that of business partners on its decisions and vice versa which may lead to sub-optimal decisions from a global point of view. In this sense, SCsCo that is able to synchronize activities between the participating echelons SCs on one hand, and between them and their third parties on the other, all participating in a global SC framework, is necessary in order to optimize the total system's performance. Therefore, in order to enhance the competitiveness in the global market, SCsCo should incorporate the financial issues of the third parties, such as their price policies, in the decision-making process of the interacting centralized SC enterprise, based on the trade-off 
between the $3^{\text {rd }}$ parties marketing and the SC functions. In this context, economic issues are usually considered as the main driving force for decision-making and, since demand is a price sensitive variable (Viswanathan and Wang, 2003), price discounts are used as a way to face global market competitiveness. The use of price discounts may lead to a higher demand which, in turn, will probably allow negotiating lower resources prices for the SC of interest. Price discounting is thus an essential strategy to be considered during SCM, since it is able to lead to more effective solutions through appropriate SCsCo.

Prices, as dynamic marketing variables, affect the products' demand, and thus any pricing decision will affect the market. To the best of our knowledge, only few PSE models in the literature consider financial issues based on pricing decisions: Weng (1995) started to use the demand elasticity as a discounting methodology, facilitating the equilibrium between the selling price of a manufacturer and the quantity demanded by different homogeneous retailers. Viswanathan and Wang (2003) use the quantity discounts methodology based on demand elasticity for single-vendor single-retailer distribution channel. They assume that both vendor and retailer act independently to maximize their own profits, the vendor is offering price discounts to the retailer, and unlike Weng (1995), the equilibrium point is determined by the solution of a Stackelberg game. Wang (2005) extends the traditional quantity discounts, which are based on market orders, by including the markets' annual volume for the SC two-echelon distribution. However, all of the aforementioned literature focuses on simple SC structures, disregarding the arising complexity when many echelons are participating in the SC of interest, including different competitive third parties, with their own policies. The links among several SCs within a global network are characterized by their economic transactions, and they are mainly modeled by average fixed parameters or based on price elasticity of demand at the final markets, disregarding the pricing behavior of the third party's resources leading to less efficient tactical decision-making, which may affect the whole SC equilibrium. Finally, none of these works integrate the third parties financial policies in the global SC decision-making as part of the modeling procedure at the tactical SCM level, which will be the focus of this paper.

So, in order to perform this analysis, and to improve the coordination among different echelons SCs in a production-distribution SC network and different competitive third parties, a decision-making framework is proposed to integrate the information of the resource flows as full SCs within the global SC structure and using this framework, the resources and financial flows of the third parties are considered as an extra degree of freedom by using different price approximation models to estimate the price policy of each participating third party. The different third parties compete through their different price polices (with price discounts based on demand elasticity theory). These approximation models are based on fixed, piecewise, and polynomial price vs demand functions. Different LP, NLP, and MINLP SC tactical management optimization models result from each one of these approximations, all of them focus on the minimization of the global SC total cost as an objective function. In order to more clearly assess the effects of these different models in the resulting decision making, a centralized global SC decision structure is considered for this study. 
The resulting models are also applied to a case study from a global multi-product SC, which takes into account the coordination of a power generation SC with a production/ distribution SC, with their RMs competitive suppliers (third parties) own price policies. The different proposed pricing models are used to approximate each third party price policy, and the systems are solved using different optimization packages according to the type of each model towards the global SC objective function. The results are analyzed to assess the efficiency of these alternative approaches and their consequences over the achieved optimal tactical decisions. The decisions resulting from each pricing model are studied in details to analyze the ability of these models to capture the competitiveness among the different third parties, and how this affects the global SC tactical decision-making (RM purchase, production, storage, and distribution levels).

This paper is divided into 5 sections. The introduction presented the motivation and the state of the art of this work. The second section includes the problem statement description and mathematical models. The case study and the models implementation are described in the third section. The fourth section thus includes the results and discussions. The final section summarizes the conclusions and the future research lines emerging from this work.

\section{Problem statement and modeling strategy}

\subsection{Problem description and third parties price policies}

This paper tackles a centralized global multi-echelon multi-product SC, with two main echelons SCs: the supplier production-distribution SC and the manufacturer productiondistribution SC; each one is represented as a SC management problem with its own entities (production, storage, distribution centers, and wastewater treatment plant "WWTP"). The SC produces final products to satisfy final market demands using raw materials (RM) from competitive third parties and intermediate product/s from the supplier echelon SC. The supplier echelon SC produces intermediate products to the production echelon SC and final product/s to final markets using RMs from competitive third parties (Figure 1).

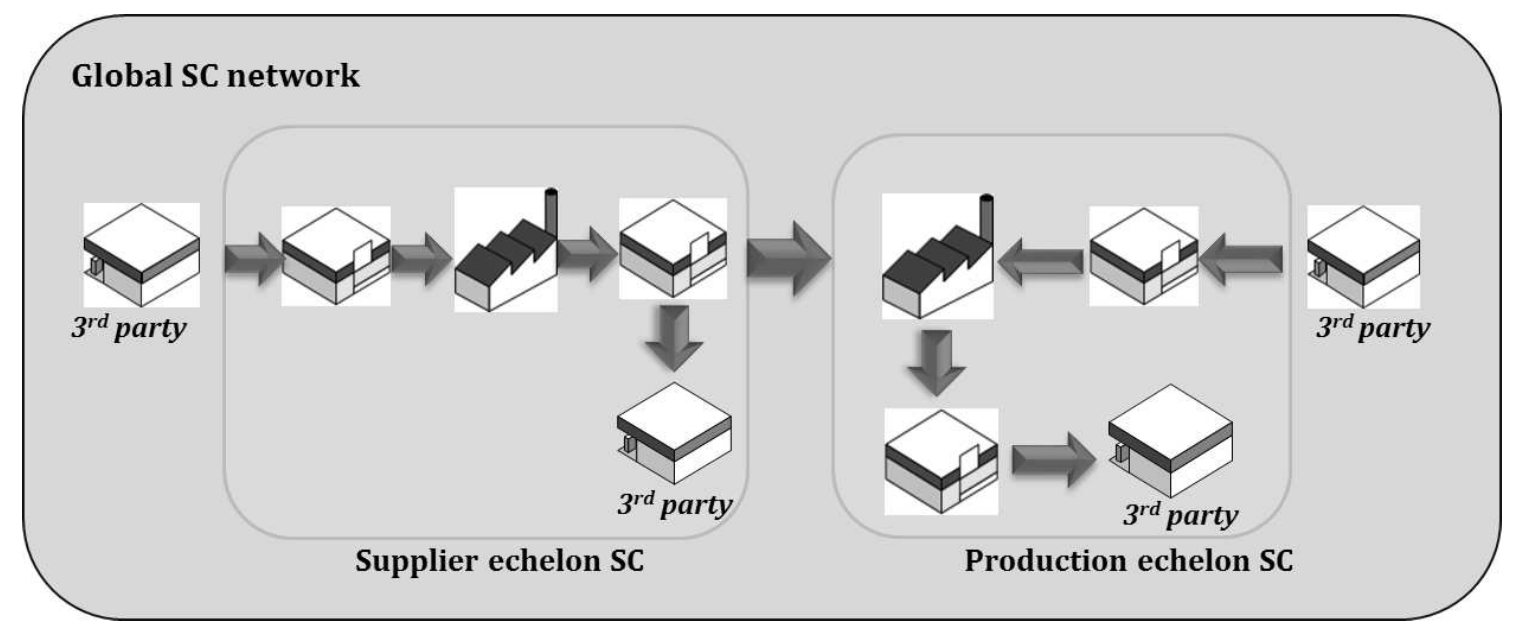


Figure 1- Global SC network and $3^{\text {rd }}$ parties

Each third party has its own price policy (Figure 2), which depends on the quantity demanded by the global system. And since these real policies are hard to model, different price approximation models are developed to estimate the price policy of each third party.

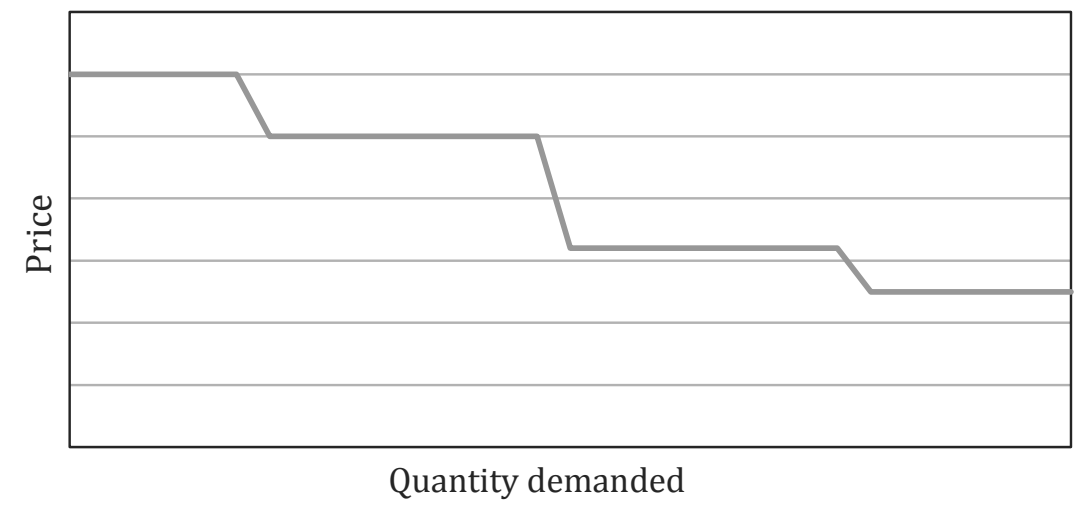

Figure 2- Price policy of $3^{\text {rd }}$ party

\subsection{Coordination modeling basis}

A generic tactical SC model is developed as a basis to test all pricing models. The model is characterized by the presence of multi-product SCs in one global SC network. These SCs, within the global SC, receive, transform, store and deliver resources from/to other echelons SCs belonging to the same global SC organization or to third party's entities (external SCs: resource suppliers, clients, waste \& recovery systems, etc.). The tactical base model incorporates all information of the participating SCs in the global SC structure, including the third parties SC's. The main objective is to achieve optimal coordination between these echelons SCs on one side, and between them and the competitive third parties on the other side, towards a common objective: to satisfy the final markets demands with minimum global cost. Within the coordination management framework, each echelon SC is able to play different roles (e.g. market in one SC and supplier for other echelons SCs along the global SC). The suppliers SCs produce intermediate products to the production/distribution SCs without any economic incomes, as they both belong to the same owner. The generic base model is then extended to include the trade-off between the external resources prices ( $3^{\text {rd }}$ parties) vs. demands through different price modeling strategies. The proposed models are developed to provide a tactical master plan, including all resources flows through the global SC network nodes and the $3^{\text {rd }}$ parties (i.e. resources purchase, price, distribution, storage, and production levels).

\subsection{Mathematical model}

The general SC coordination problem is formulated following the tactical model described by Zamarripa et al. (2014), which has been conveniently modified and adapted for the purpose of this paper. To represent the coordination framework within a centralized SC perspective, a set of echelons ( $e=e 1, e 2 \ldots E \mathrm{n})$ and their corresponding new subsets, linking the 
RMs, products, DCs, production plants, and markets to their corresponding echelons SCs are considered along the generated model.

Eq. (1) represents the coordination framework through the internal demand/production trade-off coherence between the suppliers and the production echelons, where the internal demand $\mathrm{Dmi}_{r^{\prime}, e, t}$ is calculated as a function of the production levels. $\mathrm{prf}_{r, r^{\prime}, e}$ is a production factor that depends on the efficiency of a production echelon to produce resource $r$ (final product) using resource $r^{\prime}$ (intermediate product) based on an utilized recipe (Zamarripa et al., 2014); $R$ is the set of resources produced and demanded internally or externally (intermediate/final products).

$$
\begin{aligned}
& \operatorname{Dmi}_{r^{\prime}, e^{\prime}, t}=\sum_{\substack{r \in R \\
r \neq r^{\prime}}} \operatorname{prf}_{r, r^{\prime}, e} \cdot \operatorname{prod}_{r, e, t} \\
& \forall r^{\prime} \in R ; e^{\prime} \in E ; e \in E ; t \in T
\end{aligned}
$$

The total external demand $d m d_{r, e^{\prime}, t}$ represents the final markets' satisfaction from the distribution centers as stated by Eq. (2), where $M$ represents the external markets echelon,

$$
\begin{array}{|l|l|l|}
\sum_{\substack{e \in E \\
e \neq e^{\prime}}} D_{r, e, e^{\prime}, t}=d m d_{r, e^{\prime}, t} & \forall e^{\prime} \in M ; e \in D C ; r \in R ; t \in T & \text { (2) } \\
\hline
\end{array}
$$

Eqs. (3) and (4) represent the minimum and maximum capacity constraints of the production and storage entities, respectively.

\begin{tabular}{|ll|l|}
\hline$P R D_{e, t}^{\min } \leq \sum_{r \in R} \operatorname{prod}_{r, e, t} \leq P R D_{e, t}^{\max }$ & $\forall e \in p l ; e \in E ; t \in T$ & (3) \\
\hline$S T_{e, t}^{\min } \leq \sum_{r \in R} S T_{r, e, t} \leq S T_{e, t}^{\max }$ & $\forall e \in D C ; e \in E ; t \in T$ & (4) \\
\hline
\end{tabular}

The total profit of the global SC (Eq. 5) is calculated as the difference between the total sales and the total costs of each echelon SC.

$$
P R O F=\sum_{e \in E} S A L E_{e}-C O S T_{e}
$$

The total revenues of each echelon SC $S A L E_{e}$ can be calculated by multiplying the retail price of the final product by the quantity of products demanded by the external markets (Eq. 6)

$$
S A L E_{e}=\sum_{t \in T} \sum_{r \in R} \sum_{e^{\prime} \in M} r p_{r, e^{\prime}, t} \cdot d m d_{r, e, e^{\prime}, t}
$$


The objective function Eq. (7) corresponds to the minimization of the total cost of the global SC along the considered planning horizon $T$ (resources purchase, production, storage, transport total costs, respectively).

$$
C O S T=\sum_{e \in E} C R M_{e}+C P R_{e}+C S T_{e}+C T R_{e}
$$

The total production cost $C P R_{e}$ is calculated by multiplying the total production $\operatorname{prod}_{r, e, t}$ by the unit production cost $u_{p r d}($ Eq. 8)

$$
C P R_{e}=\sum_{r \in R} \sum_{t \in T} \operatorname{prod}_{r, e, t} \text { uprd }_{r, e} \quad \forall e \in E
$$

The storage cost $C S T_{e}$ of the resources (RM, internal product, and final product) is computed built on the unit storage cost $u s t_{r, e}$ of resource $r$ in DC each planning time period $t$ (Eq. 9).

$$
C S T_{e}=\sum_{t \in T} \sum_{r \in R} S T_{r, e, t} \cdot u_{i s} t_{r, e} \quad \forall e \in E ; e \in D C
$$

The transport cost $C T R_{e}$ is calculated in terms of the travel distance dist $t_{r, e}$ for each resource and the unit transport cost $u t r_{r, e}$ (Eq. 10). $Q R_{r, e, t}$ represents the transported resources each time period $t$.

$$
C T R_{e}=\sum_{r \in R} \sum_{t \in T} Q R_{r, e, t} \cdot \operatorname{dis}_{r, e} \cdot u t r_{r, e} \quad \forall e \in E
$$

The external resources acquisition $\operatorname{cost} C R M_{e}$ from the third parties is calculated in function of the quantity demanded $\left(Q_{r, e^{\prime}, e, t}\right)$ and price $\left(P_{r, e^{\prime}, t}\right)$, as in Eq. (11), which depends on the selected pricing model, Where $S$ refers to the external resources suppliers (third parties). Eq. 12 represents the total resources purchased from the third parties for the centralized SC.

\begin{tabular}{|lr|l|}
\hline$C R M_{e}=\sum_{t \in T} \sum_{r \in R} \sum_{e^{\prime} \in S} P_{r, e^{\prime}, t} \cdot Q E_{r, e^{\prime}, e, t}$ & $\forall e \in E$ & (11) \\
\hline$Q_{r, e^{\prime}, t}=\sum_{e \in E} Q E_{r, e^{\prime}, e, t}$ & $\forall r \in R ; e^{\prime} \in S ; e^{\prime} \in E ; t \in T$ & (12) \\
\hline
\end{tabular}


Herewith, the third parties prices $P_{r, e^{\prime}, t}$ are considered as degrees of freedom in the generic model and thus, the generic coordination model is divided into several pricing models according to the type of the pricing modeling, as we will see in the next section.

\subsection{Pricing models}

Different pricing approximation models based on fixed, piecewise, and polynomial strategies have been considered as alternatives to adjust the resource prices depending on the supplied quantities, and incorporated to the general coordinated optimization model:

\section{i. fixed pricing model}

In this case, the price policy of the third parties correspond to a fixed price, regardless of the quantity demanded over the planning time horizon, perfectly elastic demand (Figure 3). $P_{r, e^{\prime}, t}=$ fixed values (i.e. average approximation).

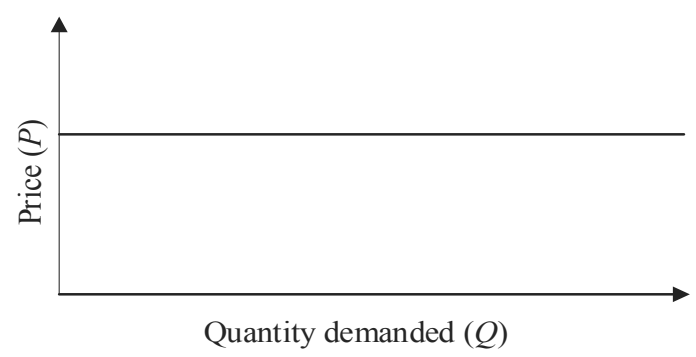

Figure 3- Fixed price vs. demand

\section{ii. Polynomial pricing model}

Based on the price elasticity of demand theory, a polynomial trend may be adjusted (Figure 4) and the resource price can be computed as in Eq. (13), where $x_{a, r}$ is a parameter which depends on the resource characteristics (initial price, supply capacity, demand elasticity, etc.).

$$
\begin{aligned}
& p_{r, e^{\prime}, t}=\sum_{a=1}^{A} x_{a, r} \cdot\left(Q_{r, e^{\prime}, t}\right)^{A-a} \\
& \forall r \in R ; e^{\prime} \in S ; e^{\prime} \in E ; t \in T
\end{aligned}
$$

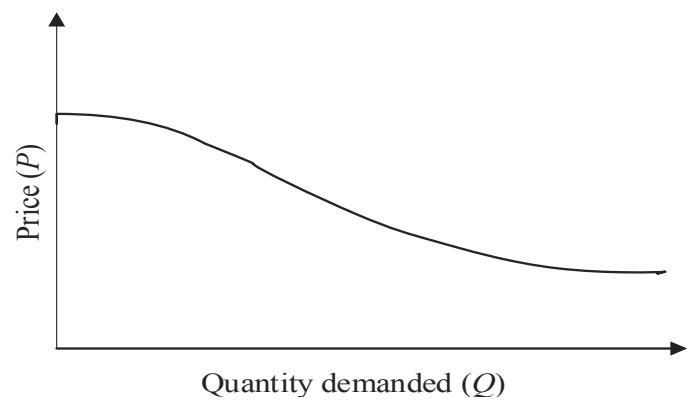


Figure 4- Polynomial price vs. demand

\section{iii. Piecewise pricing model}

It is assumed that the quantity demanded $Q$ is ordered once at any time node along the planning time horizon $T$ (Figure 5). Different pricing zones $(n=1,2, \ldots N)$ are offered by the third party depending on the quantity demanded $Q_{r, e^{\prime}, t}$ at each time period, accordingly, $Q$ has to fall in one of these $Q_{1}, Q_{2},(\ldots)$, or $Q n$.

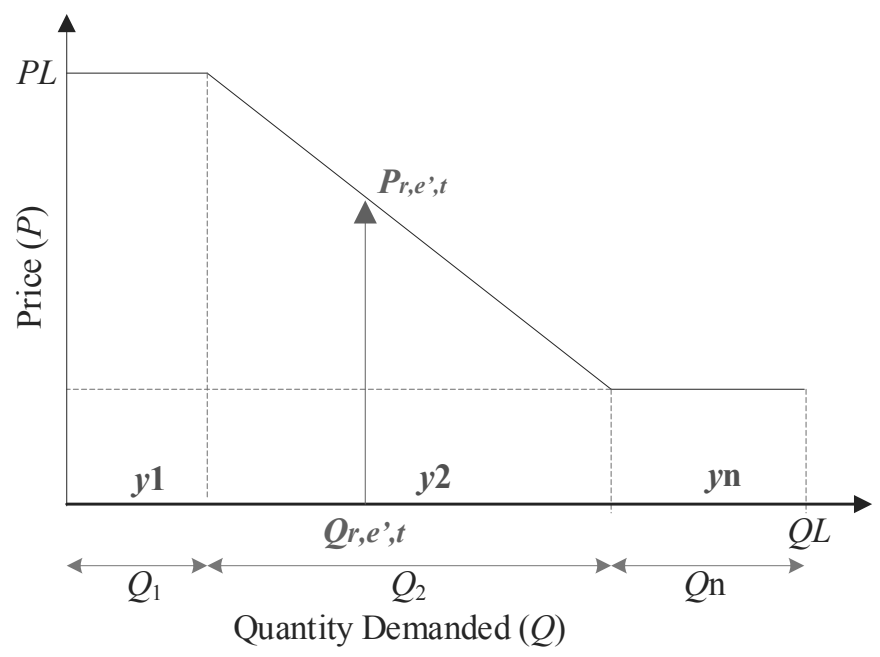

Figure 5- Piecewise price vs. demand

To do so, binary variables $(y 1, y 2 \ldots y$ n) have been used to allocate the quantity demanded to its price piece "zone" (Eq. 14).

$$
\sum_{n \in N} y_{r, e^{\prime}, t, n} \leq 1 \quad \forall r \in R ; e^{\prime} \in S ; e \in E ; t \in T
$$

Eq.15 identifies the resource quantities ranges (as constraints) and their correspondent binary variables, where $Q L_{r, e^{\prime}, t, n}$ is the maximum quantity demanded at price zone $n$.

$y_{r, e^{\prime}, t, n} \cdot Q L_{r, e^{\prime}, t, n-1} \leq Q N_{r, e^{\prime}, t, n} \leq Q L_{r, e^{\prime}, t, n} \cdot y_{r, e^{\prime}, t, n} \quad \forall r \in R ; e^{\prime} \in S ; e \in E ; t \in T ; n \in N$

The total external resource (3rd party) quantity can be computed as in Eq. 16; in which at any time node, $Q_{r, e^{\prime}, t}$ is equal to $Q 1_{r, e^{\prime}, t}$ or $Q 2_{r, e^{\prime}, t}$ or $Q n_{r, e^{\prime}, t}$

$Q_{r, e^{\prime}, t}=\sum_{n \in N} Q N_{r, e^{\prime}, t, n}$

$\forall r \in R ; e^{\prime} \in S ; e \in E ; t \in T$ 
In this later case, the price elasticity coefficient $P E_{r, e^{\prime}, t, n}$ is considered as in Gwartney et al. (2012) (Eq. 17).

$$
P E_{r, e^{\prime}, t, n}=\frac{\% \Delta Q N_{r, e^{\prime}, t, n}}{\% \Delta P N_{r, e^{\prime}, t, n}} \quad \forall r \in R ; e^{\prime} \in S ; e \in E ; t \in T ; n \in N
$$

The resources price $P N_{r, e^{\prime}, t, n}$ limits according to each pricing zone are calculated as in Eq. 18, where $P L_{r, e^{\prime}, t, n}$ is the price constraint at any price zone.

$$
\begin{aligned}
& y_{r, e^{\prime}, t, n} \cdot P L_{r, e^{\prime}, t, n} \leq P N_{r, e^{\prime}, t, n} \leq P L_{r, e^{\prime}, t, n-1} \cdot y_{r, e^{\prime}, t, n} \\
& \forall r \in R ; e^{\prime} \in S ; e \in E ; t \in T ; n \in N
\end{aligned}
$$

The resources price $P_{r, e^{\prime}, t}$ then is computed as in Eq. 19,

$$
\begin{aligned}
& P_{r, e^{\prime}, t}=\sum_{n \in N} P N_{r, e^{\prime}, t, n} \\
& \forall r \in R ; e^{\prime} \in S ; e^{\prime} \in E ; t \in T
\end{aligned}
$$

The proposed pricing models resulting in LP (fixed pricing), NLP (polynomial pricing), and MINLP (piecewise pricing) formulations are solved to minimize the cost of the global system, so decisions are to be taken at each time node such as resource purchase levels and prices, storage levels, production levels, distribution levels, transportation flows and directions, etc.

\section{Case study}

The developed LP/NLP/MINLP pricing models have been implemented to a case study modified from the one proposed by Zamarripa et al. (2014). The global SC network (Figure 6) integrates a typical polystyrene production/distribution SC (SC1) and energy generation SC $(S C 2)$. One RM supplier of wood pellets (b1), petcock (b2), marc waste (b3), and coal (b4) feeds 6 energy generation plants $(p 1, p 2 \ldots p 6)$ (see Table 1$)$. Four RM suppliers are competing to provide the polystyrene production plants $(p l 1, p l 2, p l 3)$ with alternative resources $(r m 1$, $r m 2, r m 3, r m 4$ ) in order to produce two final products: product $A$, and product $B ; r m 1$ and $r m 2$ to produce product $\mathrm{A}, \mathrm{rm} 3$ and $r m 4$ to produce product $\mathrm{B}$. The final products are stored in two distribution centers $(d c 1, d c 2)$ and later distributed to the final polystyrene markets ( $m 1, m 2, m 3$ ) (Figure 5). The energy generation echelon SC has the possibility to sell energy to the electricity local network (Grid), and the polystyrene production-distribution SC has the possibility to purchase energy from the electricity local network (Grid). It has been assumed that there is a Wastewater Treatment Plant (WWTP) in the polystyrene production sites to treat the wastewater generated from the polystyrene production. 


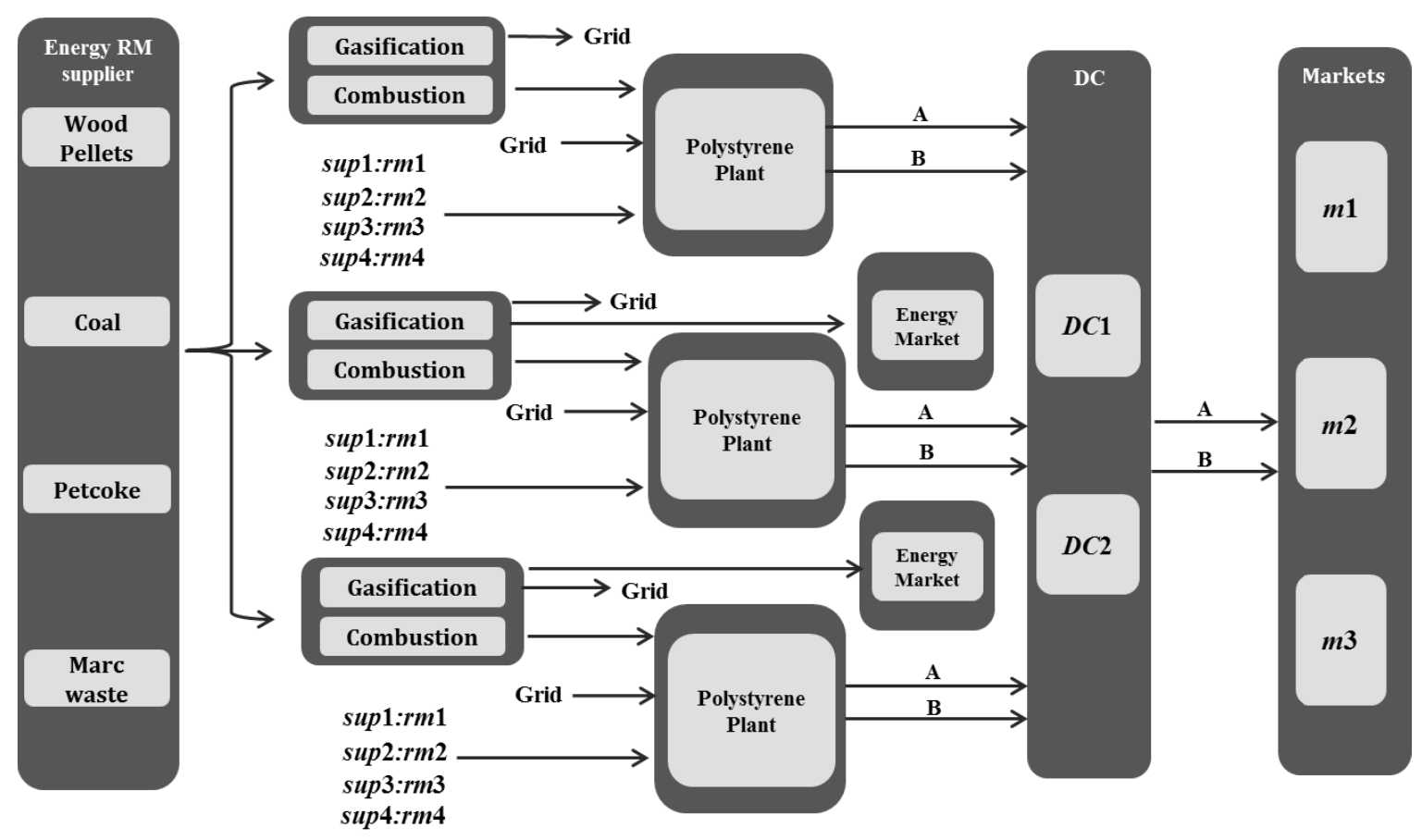

Figure 6- The global SC network

Table 1. Energy SC parameters (energy generation echelon SCs)

\begin{tabular}{lcccc}
\hline \multirow{2}{*}{$\begin{array}{l}\text { Energy required } \\
\text { resource }\end{array}$} & \multicolumn{2}{c}{$\begin{array}{c}\text { Energy production cost } \\
(€ / \mathrm{kWh})\end{array}$} & $\begin{array}{c}\text { Energy production ratio } \\
(\mathrm{kWh} / \mathrm{kg} \mathrm{RM})\end{array}$ \\
\cline { 2 - 5 } & $\begin{array}{c}\text { Gasification } \\
\text { plants }\end{array}$ & $\begin{array}{c}\text { Combustion } \\
\text { plants }\end{array}$ & $\begin{array}{c}\text { Gasification } \\
\text { plants }\end{array}$ & $\begin{array}{c}\text { Combustion } \\
\text { plants }\end{array}$ \\
\hline$b 1$ (Wood pellets) & 0.26 & 0.13 & 0.73 & 1.50 \\
$b 2$ (Coal) & 0.20 & 0.14 & 2.00 & 2.60 \\
$b 3$ (Petcock) & 0.21 & 0.15 & 0.85 & 1.80 \\
$b 4$ (Marc waste) & 0.23 & 0.135 & 0.80 & 2.00 \\
\hline
\end{tabular}

Table 2. Distance between suppliers and polystyrene production plants (km)

\begin{tabular}{cccc}
\hline \multirow{2}{*}{$\begin{array}{c}\text { Polystyrene } \\
\text { SC supplier }\end{array}$} & \multicolumn{3}{c}{$\begin{array}{c}\text { Distance to production } \\
\text { plants (km) }\end{array}$} \\
\cline { 2 - 4 } & $p l \_1$ & $p l \_2$ & $p l-3$ \\
\hline sup-1 & 100 & 150 & 145 \\
sup-2 & 200 & 120 & 130 \\
sup-3 & 110 & 70 & 80 \\
sup-4 & 170 & 220 & 215 \\
\hline
\end{tabular}




\subsection{Pricing models implementation}

Arbitrarily complex Price policies have been assumed to be known along the planning time horizon for each third party (based on current market prices ranges). These different pricing strategies have been approximated (Figures $7 \& 8$ ), resulting in four pricing models: average fixed, quartic polynomial, linear polynomial, and piecewise, to be used during the optimization of the planning decisions for the SC of interest.

a)

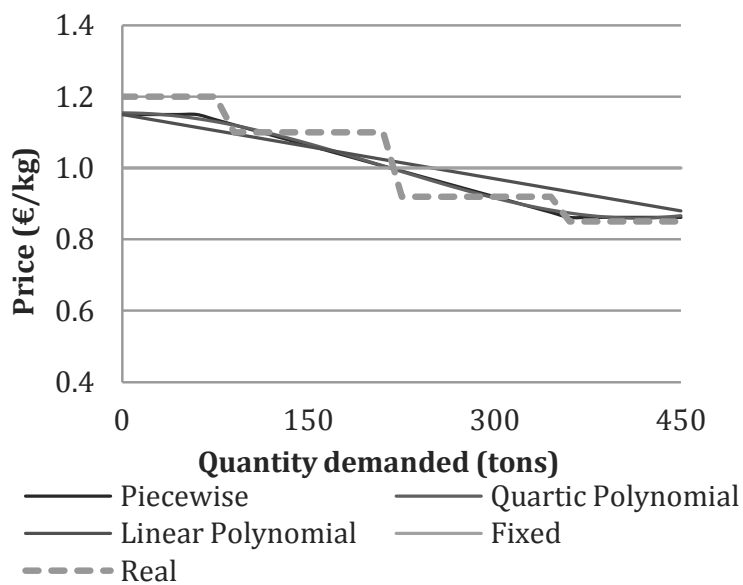

c)

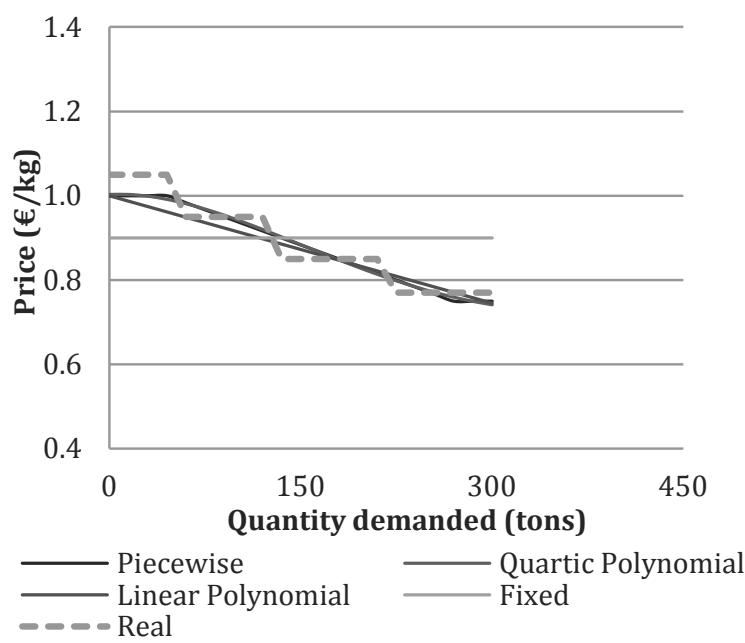

b)

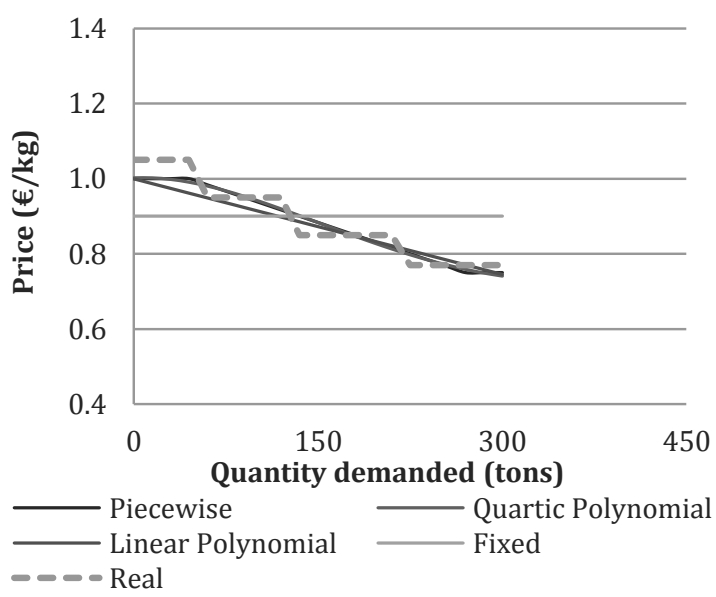

d)

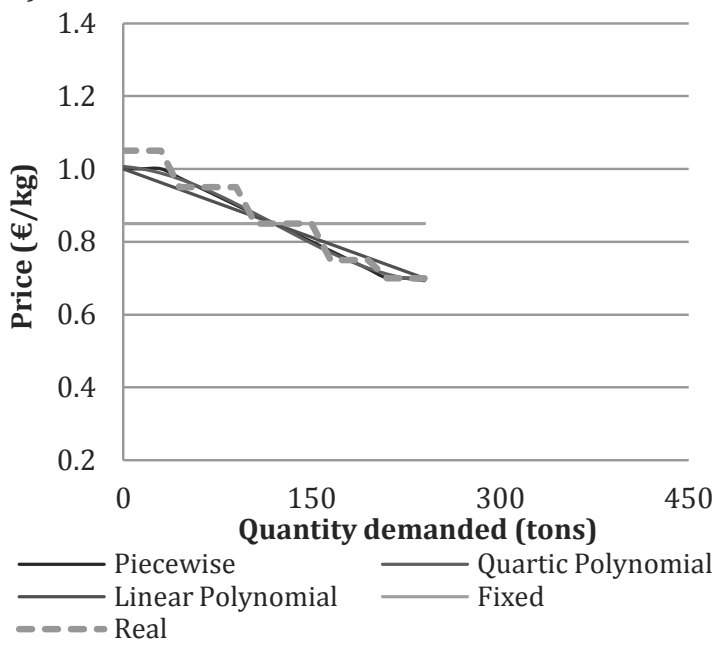

Figure 7- Polystyrene SC RM pricing trends
a) $r m 1$
b) $r m 2$
c) $\mathrm{rm} 3$
d) $\mathrm{rm} 4$ 
a)

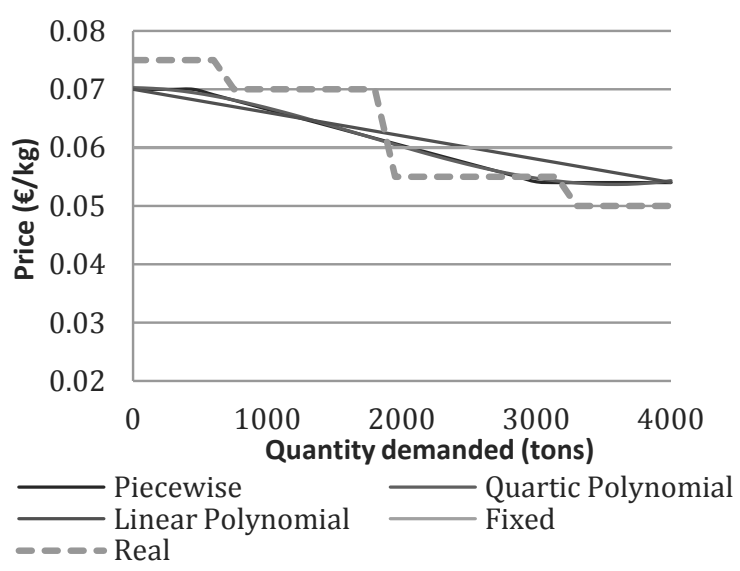

c)

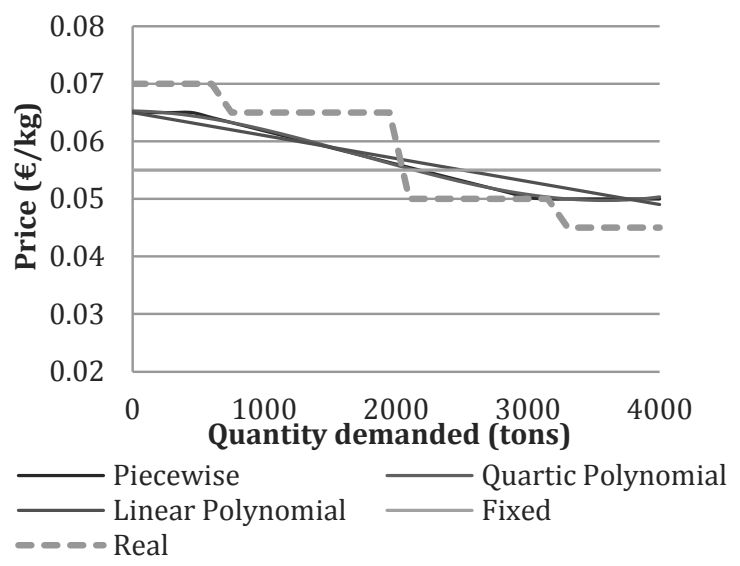

b)

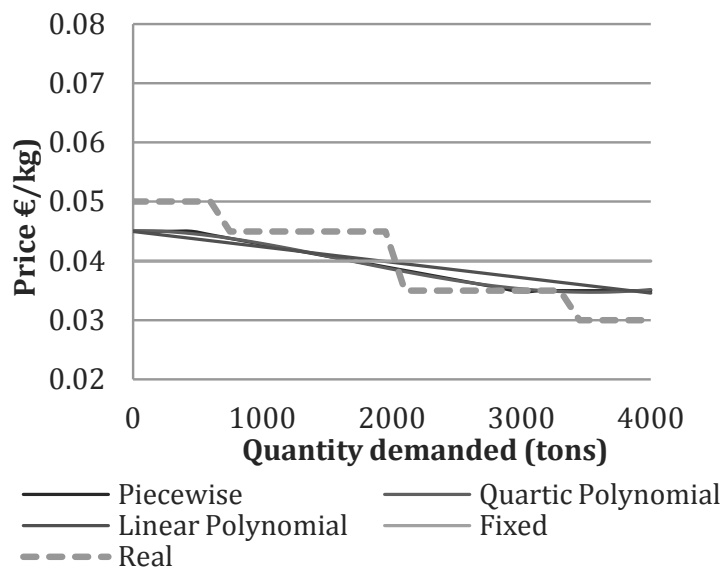

d)

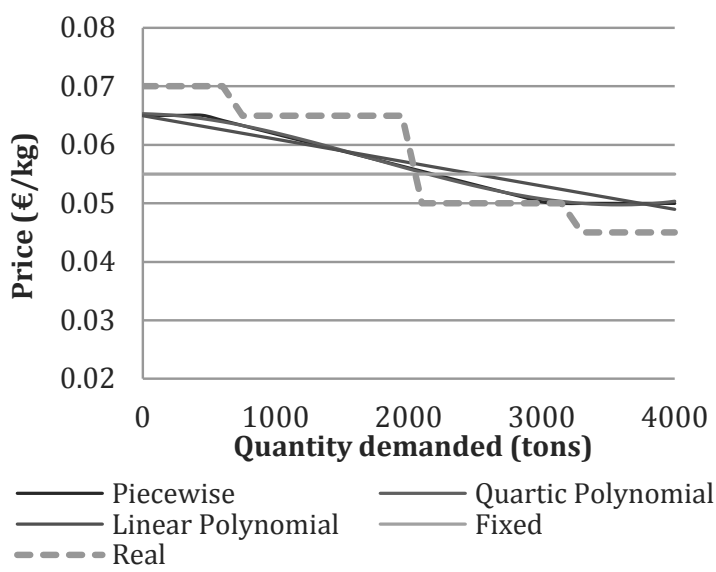

Figure 8- Energy SC RM pricing patterns

a) wood pellets b) petcock c) marc waste d) coal

\section{i) Fixed pricing model}

For the fixed pricing model, the average between the highest and the lowest real prices have been considered for each RM under study (Table 3).

Table 3- Global SC RM fixed prices

\begin{tabular}{cc}
\hline \multicolumn{2}{c}{ Fixed Prices } \\
\hline Raw Materials & Price $(€ / \mathrm{kg})$ \\
\hline$r m 1$ & 1.00 \\
$r m 2$ & 0.90 \\
$r m 3$ & 0.90 \\
$r m 4$ & 0.85 \\
$b 1$ & 0.060 \\
$b 2$ & 0.040 \\
$b 3$ & 0.065 \\
$b 4$ & 0.055 \\
\hline
\end{tabular}




\section{ii) Polynomial pricing models}

Two polynomial pricing strategies are analyzed here with different degrees: quartic polynomial (a polynomial of degree 4) and linear polynomial (a polynomial of degree 1) (Figures 7 and 8). Table 4 illustrates the parameters that substitute Eq. 8 in the proposed mathematical model. The polynomial parameters are obtained after adjusting the polynomial trends to each price policy.

Table 4- RM polynomial-model parameters

\begin{tabular}{|c|c|c|c|c|c|c|c|}
\hline & \multicolumn{5}{|c|}{ Quartic Polynomial } & \multicolumn{2}{|c|}{ Linear Polynomial } \\
\hline & \multicolumn{5}{|c|}{$(A=5)$} & \multicolumn{2}{|c|}{$(A=2)$} \\
\hline & $x 1$ & $x 2$ & $x 3$ & $x 4$ & $x 5$ & $x 1$ & $x 2$ \\
\hline \multicolumn{8}{|c|}{ Polystyrene production SC } \\
\hline$r m 1$ & $8.43 \mathrm{E}-25$ & $7.61 \mathrm{E}-18$ & $-5.03 \mathrm{E}-12$ & $5.04 \mathrm{E}-09$ & 1.155 & $-6.0 \mathrm{E}-07$ & 1.15 \\
\hline$r m 2$ & $-2.32 \mathrm{E}-23$ & $2.95 \mathrm{E}-17$ & $-1.01 \mathrm{E}-11$ & $1.43 \mathrm{E}-07$ & 1.003 & $-8.5 E-07$ & 1.00 \\
\hline$r m 3$ & $-2.32 \mathrm{E}-23$ & $2.95 \mathrm{E}-17$ & $-1.01 \mathrm{E}-11$ & $1.43 \mathrm{E}-07$ & 1.003 & $-8.5 \mathrm{E}-07$ & 1.00 \\
\hline$r m 4$ & 0 & $3.68 \mathrm{E}-17$ & $-1.33 \mathrm{E}-11$ & $-2.50 \mathrm{E}-07$ & 1.007 & $-1.25 \mathrm{E}-6$ & 1.00 \\
\hline \multicolumn{8}{|c|}{ Energy generation SC } \\
\hline$b 1$ & $-2.5 E-29$ & $8.82 E-22$ & $-4.05 \mathrm{E}-15$ & $-2.89 \mathrm{E}-10$ & 0.070 & $-4.0 \mathrm{E}-09$ & 0.070 \\
\hline$b 2$ & $-3.6 \mathrm{E}-29$ & $7.33 \mathrm{E}-22$ & $-3.01 \mathrm{E}-15$ & $1.26 \mathrm{E}-10$ & 0.045 & $-2.6 \mathrm{E}-09$ & 0.045 \\
\hline$b 3$ & $-3.6 \mathrm{E}-29$ & $1.03 \mathrm{E}-21$ & $-4.54 \mathrm{E}-15$ & $-1.54 \mathrm{E}-10$ & 0.075 & $-4.5 \mathrm{E}-09$ & 0.075 \\
\hline$b 4$ & $-1.3 E-29$ & $7.36 \mathrm{E}-22$ & $-3.56 \mathrm{E}-15$ & $-4.25 \mathrm{E}-10$ & 0.065 & $-4.0 \mathrm{E}-09$ & 0.065 \\
\hline
\end{tabular}

iii) Piecewise linear pricing model

Three pricing zones are assumed to be offered by the third parties for each RM feeding the SC of interest. The price elasticity of demand for the first and the third prices zones $(n=1$ $\& 3)$ is equal to zero, while the price elasticity of demand $(P E)$ at price zone $(n=2)$ has been considered as (-20) for all RMs feeding the polystyrene production SC, and (-25) for all RMs feeding the energy generation SC. Table 5 illustrates the prices and quantities ranges.

Table 5- Piecewise-model parameters

\begin{tabular}{cccccc}
\hline & RM price ranges $(€ / \mathrm{kg})$ & \multicolumn{3}{c}{ RM purchased ranges (tons) } \\
\hline & max price & min price & $\begin{array}{c}\text { when price } \\
\text { discount starts }\end{array}$ & $\begin{array}{c}\text { when price } \\
\text { discount stops }\end{array}$ & $\begin{array}{c}\text { max supplier } \\
\text { capacity } Q_{\max }\end{array}$ \\
\hline $\begin{array}{c}\text { Polystyrene } \\
\text { production SC }\end{array}$ & & & & & \\
rm1 & 1.15 & 0.86 & 60 & 360 & 450 \\
rm2 & 1.00 & 0.75 & 45 & 270 & 300 \\
rm3 & 1.00 & 0.75 & 45 & 270 & 300 \\
rm4 & 1.00 & 0.70 & 30 & 210 & 240 \\
Energy & & & & & \\
generation SC & 0.070 & 0.054 & 450 & 3,000 & 4,000 \\
$b 1$ & 0.045 & 0.035 & 450 & 3,000 & 4,000 \\
$b 2$ & 0.075 & 0.058 & 450 & 3,000 & 4,000 \\
$b 3$ & 0.065 & 0.050 & 450 & 3,000 & 4,000 \\
\hline$b 4$ & & & & & \\
\hline
\end{tabular}




\section{Results and discussion}

The proposed pricing models, within the coordination framework, have been solved for the above-mentioned case study, taking into consideration material/energy balances, processes availability, capacities and constraints, and tasks over a time horizon of 10 time periods; 1000 working hours each. The solution procedure is divided into two main steps:

I) Optimization: Each pricing approximation is used to build a model which is optimized according to the established objective function (total cost), resulting in an optimal RM flow distribution Q from the 3rd parties over the discrete planning horizon for each pricing approximation.

II) Simulation: These optimal RM distributions (from step I) are used to compute their real prices each time period (here, the 3rd party's real prices policies are assumed as in Figures 7 and 8). Then, with the proposed $Q$ distributions and their real prices, the pricing approximation models are simulated to obtain the associated total costs, so a comparison between the real expected costs is conducted.

The resulting LP, NLP, and MINLP models have been modelled using GAMS and solved using Global mixed-integer quadratic optimizer "GloMIQO (Misener \& Floudas, 2013)" on a Windows 7 computer with Intel ${ }^{\circledR}$ Core $^{\mathrm{TM}} \mathrm{i} 7-2600 \mathrm{CPU} 3.40 \mathrm{GHz}$ processor with 16.0 GB of RAM. The results show that the SCs coordination and the tactical decisions are affected by the quality of the price modeling selected.

\subsection{Results for SC1: Polystyrene production}

The pricing models affect the tactical decisions of $S C 1$; the results show how the RM purchase levels vary according to the pricing modeling. The $r m 1$ and $r m 2$ suppliers (third parties) are competing to produce polystyrene product A, while $r m 3$ and $r m 4$ suppliers (third parties) are competing to supply for producing polystyrene product B. Figure 9 shows that $r m 2$ and $r m 4$ dominate the RM purchase levels using most of the pricing models, except in the piecewise model. The purchase levels of $r m 2$ are the winners of the competence for all pricing models (Figure 9), as it has lower prices than rm1, and is the closest supplier to the dominating production plants ( $p l 2$ and $p l 3$ ) (see Table 2 and Figure 11). The trend using the discount pricing models is to buy high amounts of RM to get higher discounts, getting the advantage of the storage centers to store the excess products for later distribution, as we will see in the next paragraphs. This can be seen clearly in the linear polynomial model (Figure 9d); rm4 is purchased in most of the time periods at the supplier capacity level (240 tons), however, at time periods $t 1, t 3$, and $t 5$, the decision is to buy from both $r m 3$ and $r m 4$ at their maximum supplying capacities to get the least possible prices, leading to not purchasing any of $r m 4$ at time periods $t 4$ and $t 10$ suggesting to stop polystyrene B production (Figure 12d) at those time periods.

From the other hand, the trend using the fixed price modeling is to buy RM all time periods (Figure 9a), as its decision does not take into account any discounts, and that is why 
the purchase levels are distributed between all RMs along the planning time periods, except $r m 1$ due to its highest price (Table 3).

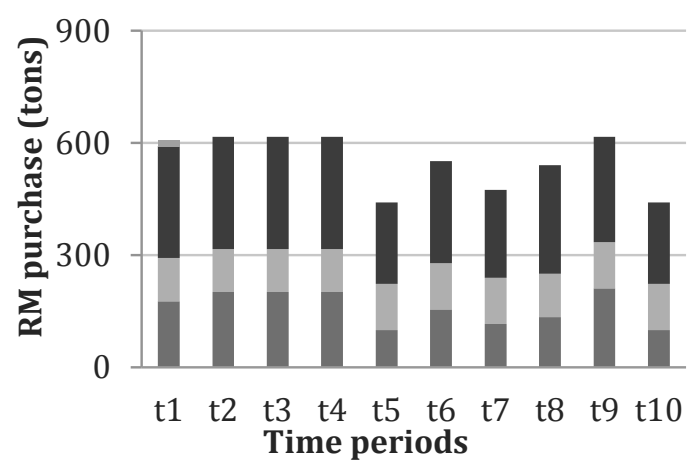

a)
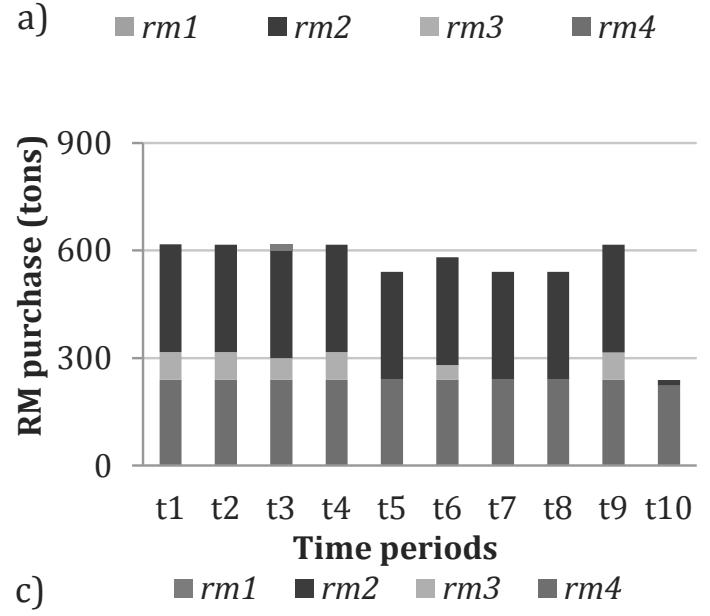

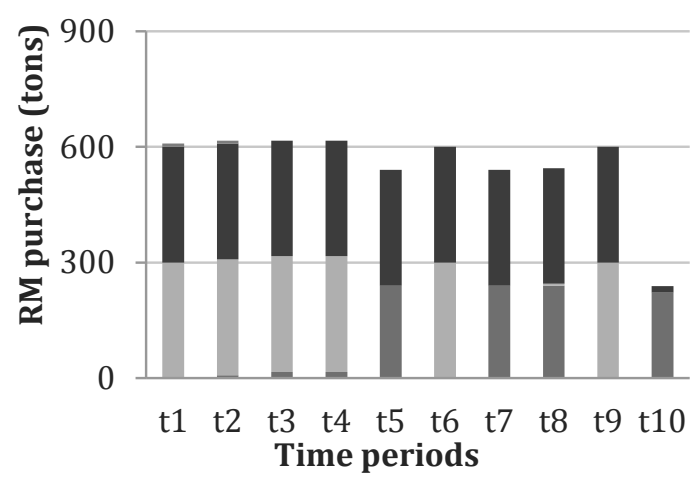

b)

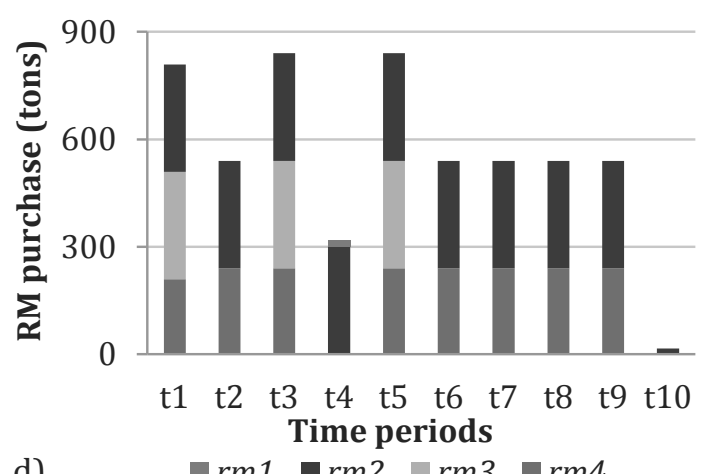

Figure 9- SC1 RM purchase levels

a) Fixed, b) Piecewise, c) Quartic Polynomial, d) Linear Polynomial

Analyzing the piecewise pricing model results (Figure 9b), rather than the other pricing models, $r m 3$ dominates the SC1 RM purchase levels most of time periods, although it has higher prices than $r m 4$, but with small difference (Figure 10b). Given the small price difference between them, the decision is to buy from the supplier whose capacity is dominated by rm3. At the contrary, $r m 2$ dominates the SC1 RM purchase levels although it has less supplying capacity than $r m 1$, but with large difference in the price (Figure 10a), so the decision here was to buy from $r m 2$ supplier at the supplier capacity (300 tons) all time periods, except at $t 10$; here it can be seen the trade-off between the supplier capacity and price. Nevertheless, buying $\mathrm{rm} 2$ at its supplier capacity most of the time periods leads to purchase very small amounts at time period $t 10$ (16.4 tons), subsequently, this leads to produce very small amounts of polystyrene product $A$ at $t 10$ (16.2 tons) (see Figure 11b), getting the advantage of the stored products to satisfy the market demand at this time period. 

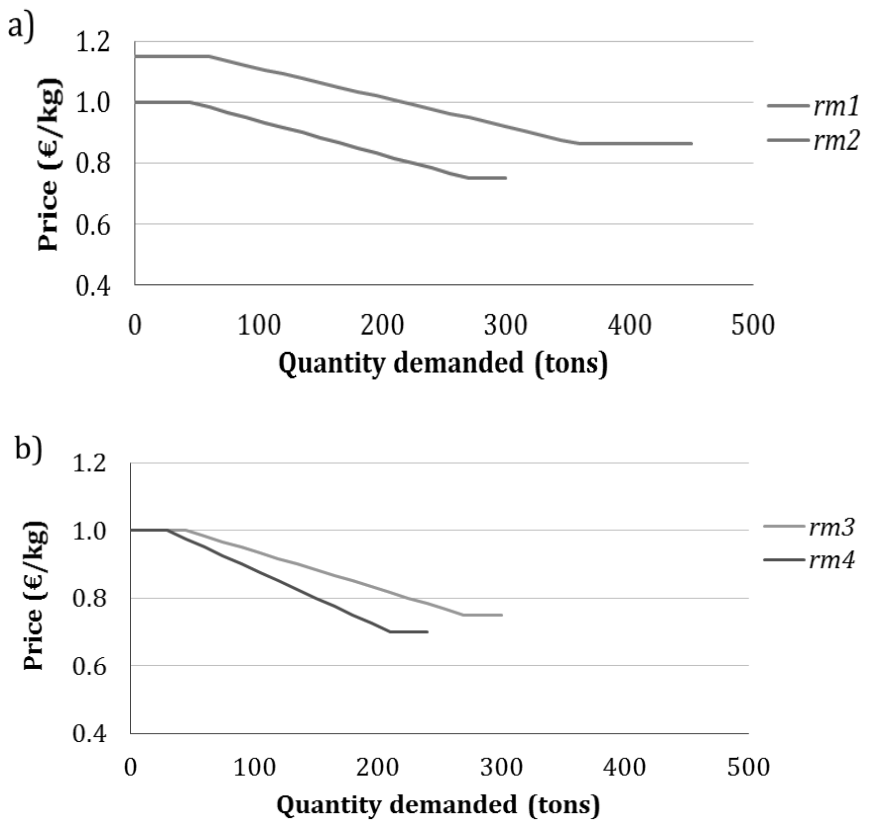

Figure 10- Piecewise approximation analysis

a) RMs to produce product $\mathrm{A}$ b) RMs to produce product $\mathrm{B}$

Producing polystyrene products A and B is the main task of the global SC. Since the RM purchase levels and their prices are degree of freedom variables, consequently, the pricing modeling affects the polystyrene production levels (Figures 11 \& 12). Since the rm2 dominates the RM purchase levels for product A. This behavior explains why the production profile of product A (Figure 11) follows the same $r m 2$ purchase trends (Figure 9) in all pricing models. The type of RM purchased, also affects the choice to operate the polystyrene production plants (produce or not). For example, as the polystyrene production plant (pl2) is the closest to the rm2 supplier location (Table 2), it is also dominating the production of product A in all pricing models.

Furthermore, the efficiency of the coordination in the supply chain is remarked in the solution of time period $t 10$ (Figure $12 \mathrm{~b}, \mathrm{c}, \& \mathrm{~d}$ ); at this time period we can observe high final market demands, while the production plants and the purchase of raw materials $r m 2$ are low. This operation scenario is due to the high raw material prices, while the product needs are being satisfied by the inventory levels (Figure 13b, c, \& d). 
a)

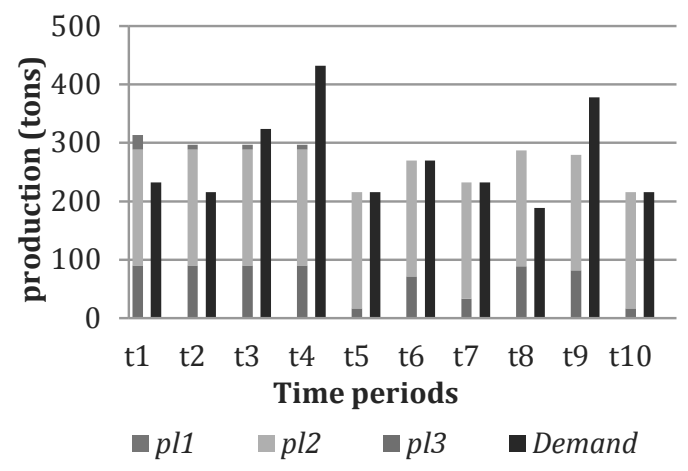

c)

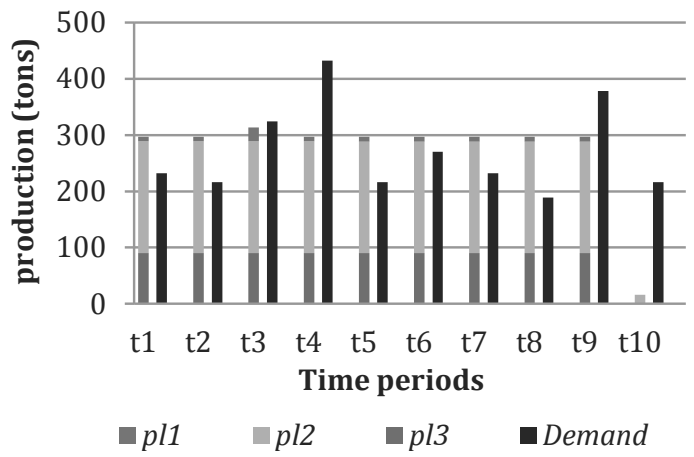

b)

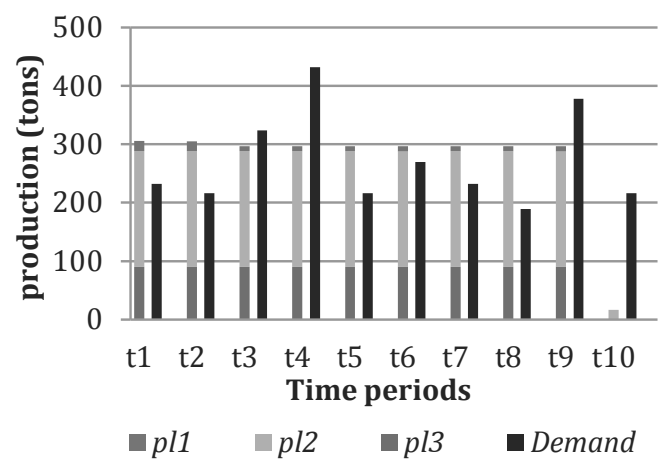

d)

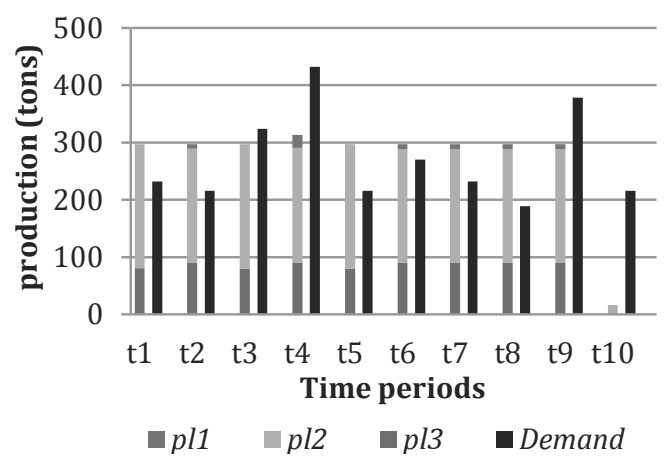

Figure 11- Product A production levels

a) Fixed, b) Piecewise, c) Quartic Polynomial, d) Linear Polynomial

Regarding product B production decisions, polystyrene production plants $p l 1$ and $p l 3$ dominate the product B production levels in most of the pricing models (Figure 12). Since rm 4 dominates the purchase levels for producing product B in most of the pricing models, and given that polystyrene plant $p l 1$ is the closest to the $r m 4$ supplier location (Table 2), pl1 dominates the production levels in the pricing models where $r m 4$ dominates the RM purchase levels. In the case of the piecewise model (Figure 12b), the $p l 1$ plant highly dominates again the production of product $\mathrm{B}$, especially for time periods $t 5, t 7, t 8$ and $t 10$, and these are the same time periods where $r m 4$ is dominating the RM purchase levels (Figure 9b).

When using the linear polynomial pricing model, the production plant $p l 2$ is operating for the first time to produce product B (Figure 12d), besides the other plants, mainly in time periods $t 1, t 3$, and $t 5$ to cope with the huge amounts of RM purchased in those time periods (see Figure 9d), since the polystyrene plant $p / 2$ is the closest to the $r m 3$ supplier (Table 2), thus showing the role of transport in the tactical decision-making. 
a)

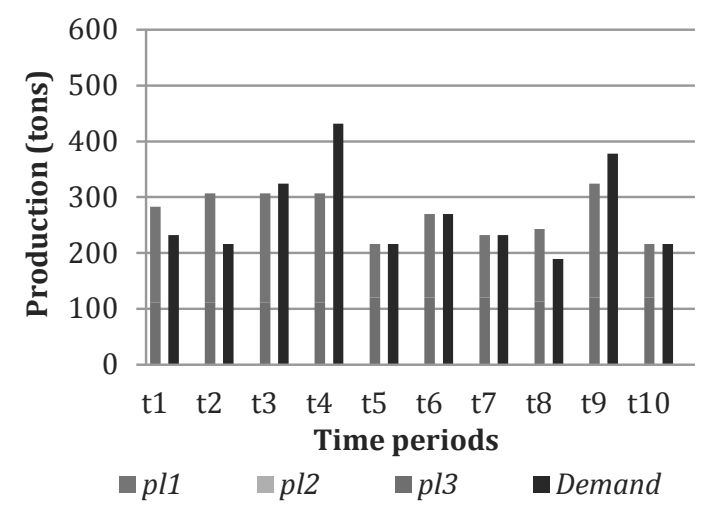

c)

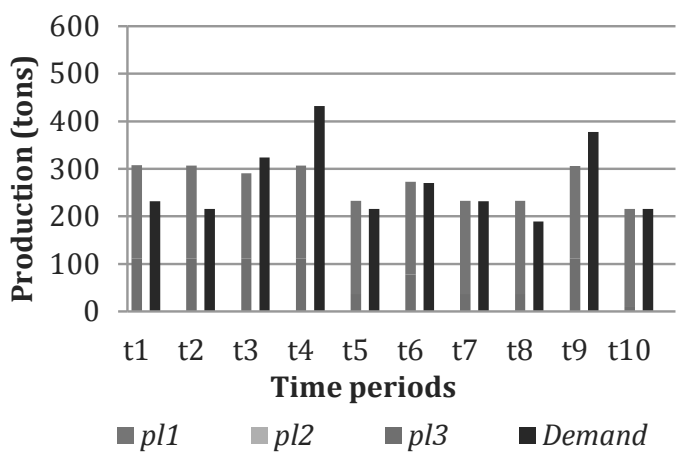

b)

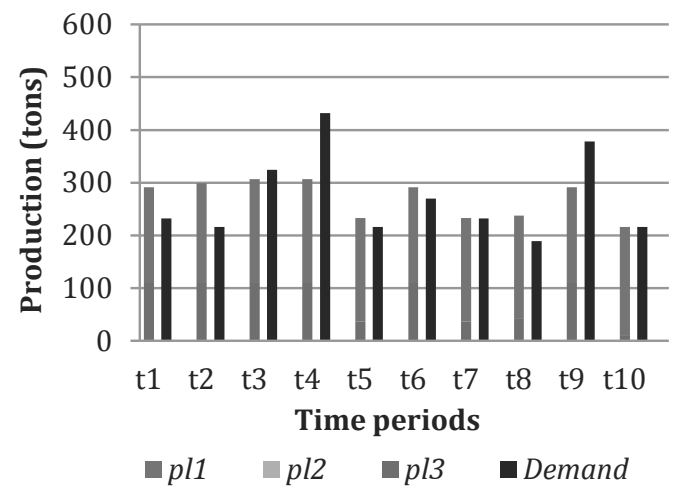

d)

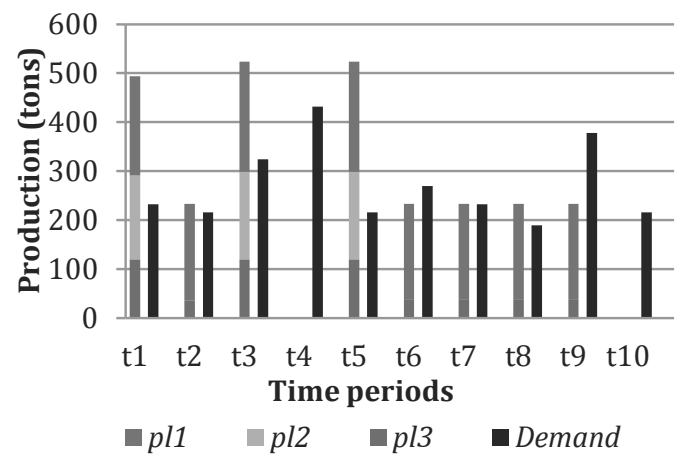

Figure 12- Product B production levels

a) Fixed, b) Piecewise, c) Quartic Polynomial , d) Linear Polynomial

The storage actions play a crucial role in this problem, since the pricing models drive the producers to buy higher amounts of raw materials in order to obtain higher discounts. The excess of the products is then stored to be distributed in future time periods. Figure 13 shows how the storage decisions are affected by the pricing modeling; the discounting models lead to higher storage (Figure 13b, c, \& d) than the average fixed pricing model (Figure 13a), and that is due to the higher production levels exceeding the demands in order to cope with the huge amounts of RM purchased (see Figures 9, 11, \& 12). And that explains why the linear polynomial model requires higher storage level (3802 tons) compared with (1721 tons, 1718 tons, and 848 tons) regarding the quartic polynomial, piecewise, and fixed pricing models, respectively. The total storage of the polystyrene products resulting from the fixed pricing model is the lowest as its pricing strategy does not take into account any discounts and thus no need for much storage.

It has been noticed that the storage levels of the product A-polystyrene resulting from the piecewise and the quartic polynomial models (Figure $13 \mathrm{~b}, \mathrm{c}$ ) are high at time periods $(t 7$, $t 8, t 9)$, where the production levels are high, and that the excess amounts will be distributed at time $t 10$ where the production levels are very low (16.20 tons; $0.60 \%$ of the total product A production): (Figures 11b, c). 


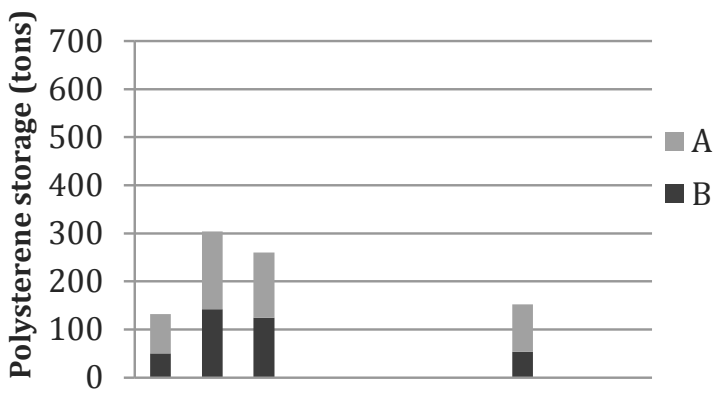

$\begin{array}{lllllllllll}\text { t1 } & \text { t2 } & \text { t3 } & \text { t4 } & \text { t5 } & \text { t6 } & \text { t7 } & \text { t8 } & \text { t9 } & \text { t10 }\end{array}$

a)

Time periods

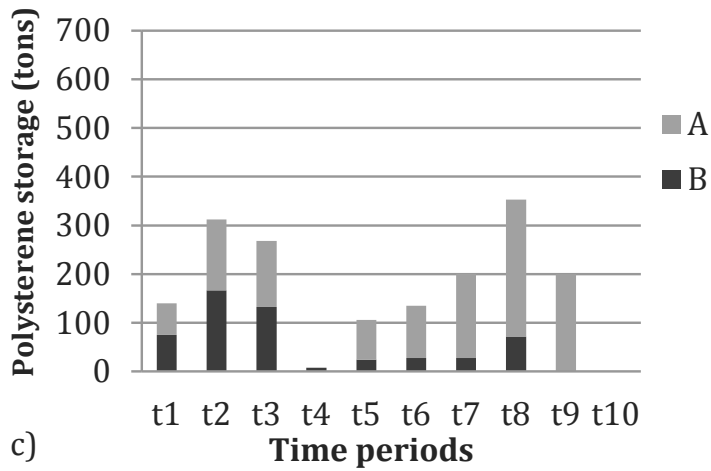

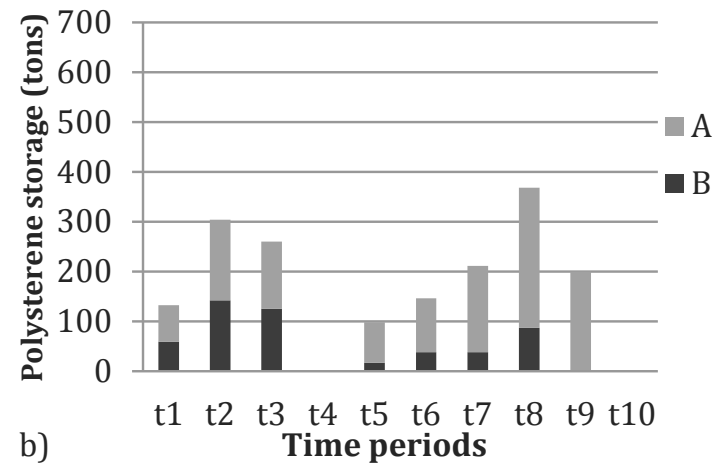

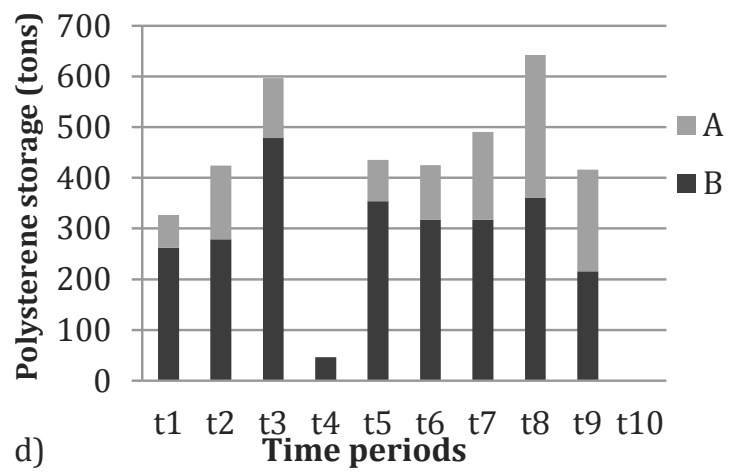

Figure 13- SC1 storage levels

a) Fixed, b) Piecewise, c) Quartic Polynomial, d) Linear Polynomial

Figure 14 shows how the energy demanded internally (the coordination item) is also affected by the pricing modelling, leading to changes in the tactical decisions of the energy generation SC. The energy demanded by $S C 1$ follows the trends of the polystyrene production levels that are already affected by the pricing modeling. For example, the internal energy demand obtained from the linear polynomial pricing model (Figure 14d) is very high at time periods $t 1, t 3$ and $t 5$ due to the high polystyrene production levels (Figure $12 \mathrm{~d}$ ).

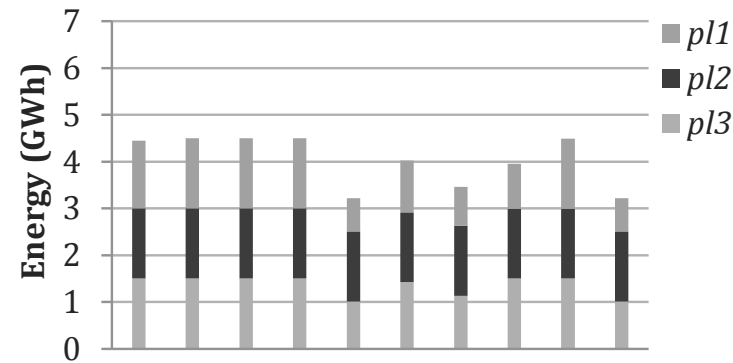

a) t1 Time periods

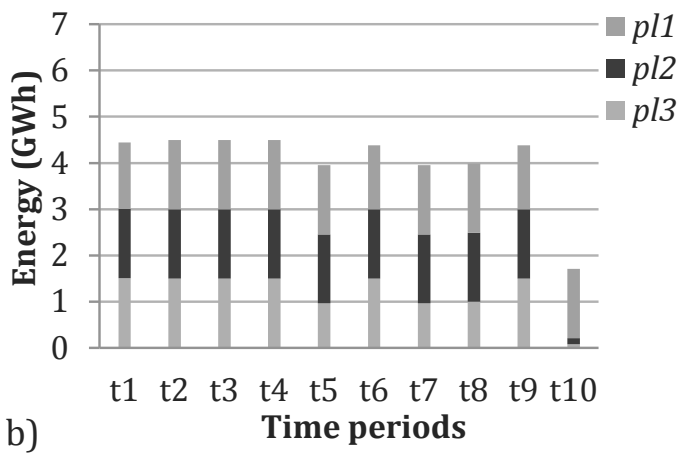



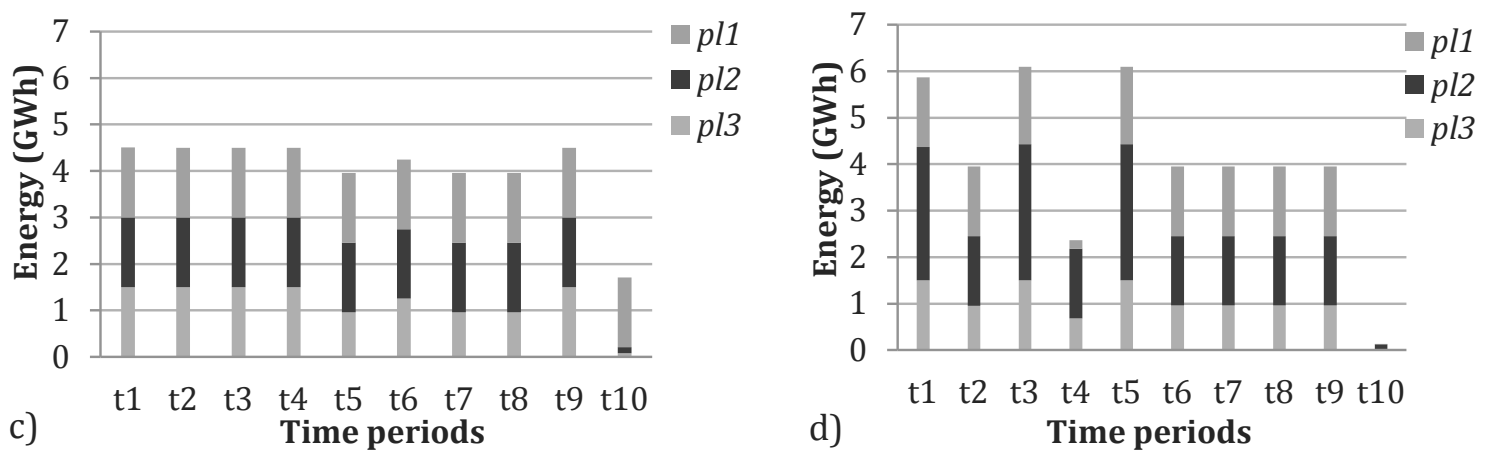

Figure 14- SC1 Internal energy demand

a) Fixed, b) Piecewise, c) Quartic Polynomial, d) Linear Polynomial

Consequentially, the decision-making behavior of SC1 affects the tactical decisions of SC2. This can be clearly seen in the next section where the tactical decisions of SC2 are analyzed.

\subsection{Results for SC2: Energy generation}

The energy required by the polystyrene SC is provided from the energy SC according to the coordination requirements. Figure 15 shows how the energy generation of the energy plants are affected by the pricing modeling. In order to fulfill the energy demanded by the markets, as observed in Figure 14, the energy generation plants by combustion $(p 4, p 5$, and p6) dominate the energy generation in all pricing models, except in the linear polynomial model. On the other side, the gasification plants ( $p 1, p 2$, and $p 3)$ are kept closed. Using the linear polynomial pricing model, requires the operation of gasification plants $p 1$ and $p 2$ at time periods $(t 1, t 3$, and $t 5)$, when the energy plants $p 4$ and $p 5$ exceed their generation capacities $(1.5 \mathrm{GW})$ in order to cope with the huge energy demand at these time periods of $S C 1$ (see Figure 14d), which requires buying high amounts of RM for SC1 (Figure 9d).

It is also to be noticed that in Figures ( $15 \mathrm{~b} \& \mathrm{c})$, the quartic polynomial and piecewise models lead to similar energy generation patterns except at time period $t 6$; the piecewise model requires the operation of energy plant $p 6$ up to its generation capacity in order to fulfill the high energy demand resulting from the operation of the $p l 3$ polystyrene plant at $t 6$ due to the high amounts of purchased $r m 3$ (see Figures $9 \mathrm{~b} \& 12 \mathrm{~b}$ ). Furthermore, the linear polynomial pricing model leads to a very small energy generation at time period $t 10$ (128.05 MWh; $0.32 \%$ of the total energy demand), because the polystyrene production is very low due to the small amounts of purchased RM at this time period. 


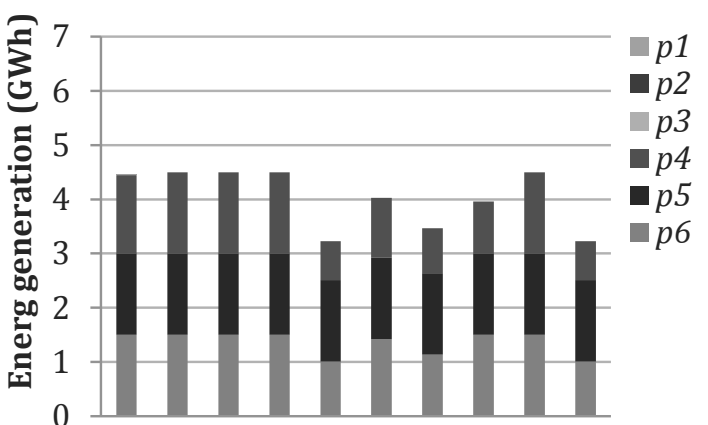

a)

$\begin{array}{llllllllll}\text { t1 } & \text { t2 } & \text { t3 } & \text { t4 } & \text { t5 } & \text { t6 } & \text { t7 } & \text { t8 } & \text { t9 } & \text { t10 }\end{array}$ Time periods

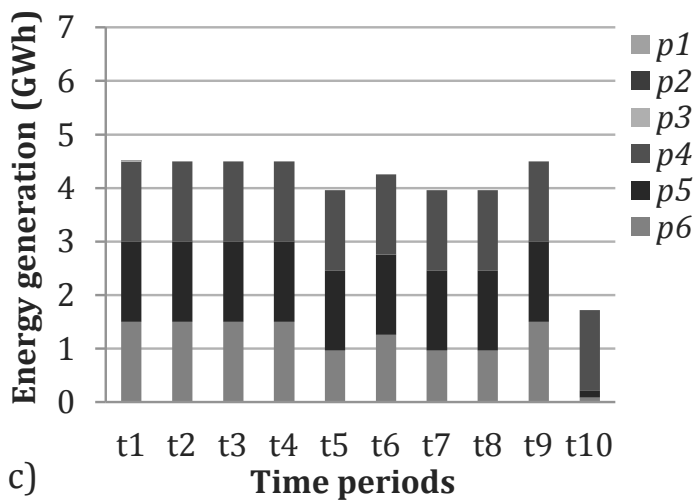

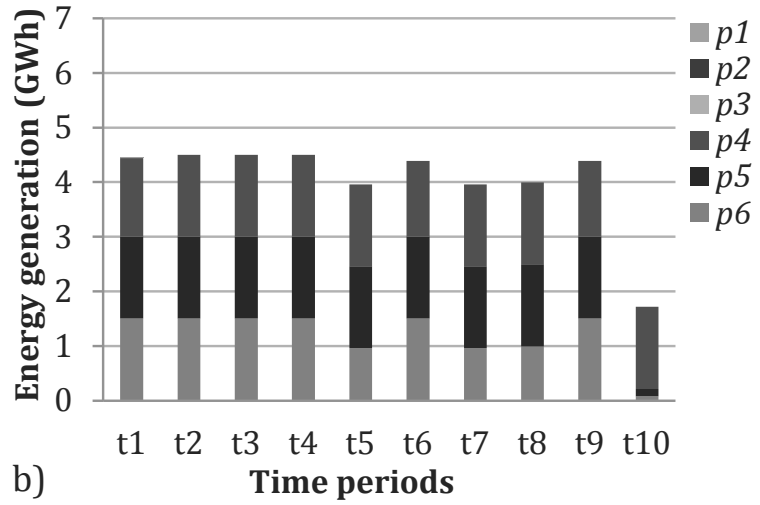

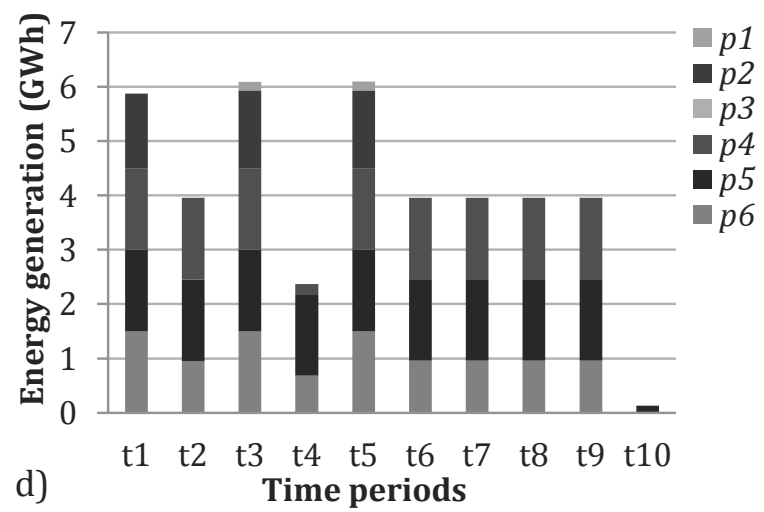

Figure 15- Energy generation levels

a) Fixed, b) Piecewise, c) Quartic Polynomial, d) Linear Polynomial

Consequently, the SC2 RM purchase decisions are affected by the pricing modelling as it is illustrated in Figure 16. To meet the energy demand of the markets, the decision is in favor of the RM $b 2$ (coal) which has been purchased in different quantities along the time periods depending on the pricing models. By reading Figure 16, it is noticed that the RM decisions suggested by the linear polynomial pricing model are different following the energy generation demands, especially at $t 1, t 3$, and $t 5$ where the RM levels purchased for $S C 1$ are the highest, resulting in demanding more energy (see Figures $9 \mathrm{~d}$ and 14d). It should also be noticed that at time period $t 10$, the discounting models result in very low purchase amounts of $b 2 ; 660$ tons for both pricing models piecewise and the quartic polynomial, and 49 tons using the linear polynomial model. The total amounts of RM purchased for SC2 according to the linear polynomial pricing model are the highest (16,042 tons), compared with 15,516 tons resulting from the other pricing models.

The reason behind the dominance of $b 2$, for all pricing models, is that the energy generation decisions lead to the operation of the energy plants ( $p 4, p 5$, and $p 6)$, where $b 2$ has the highest efficiency $(2.6 \mathrm{kWh} / \mathrm{kg})$ compared with $b 1(1.5 \mathrm{kWh} / \mathrm{kg})$, which has the lowest price $(0.13 € / \mathrm{kWh}$ ) (see Table 1 ), thus we can realize the trade-off between the prices and efficiencies. 


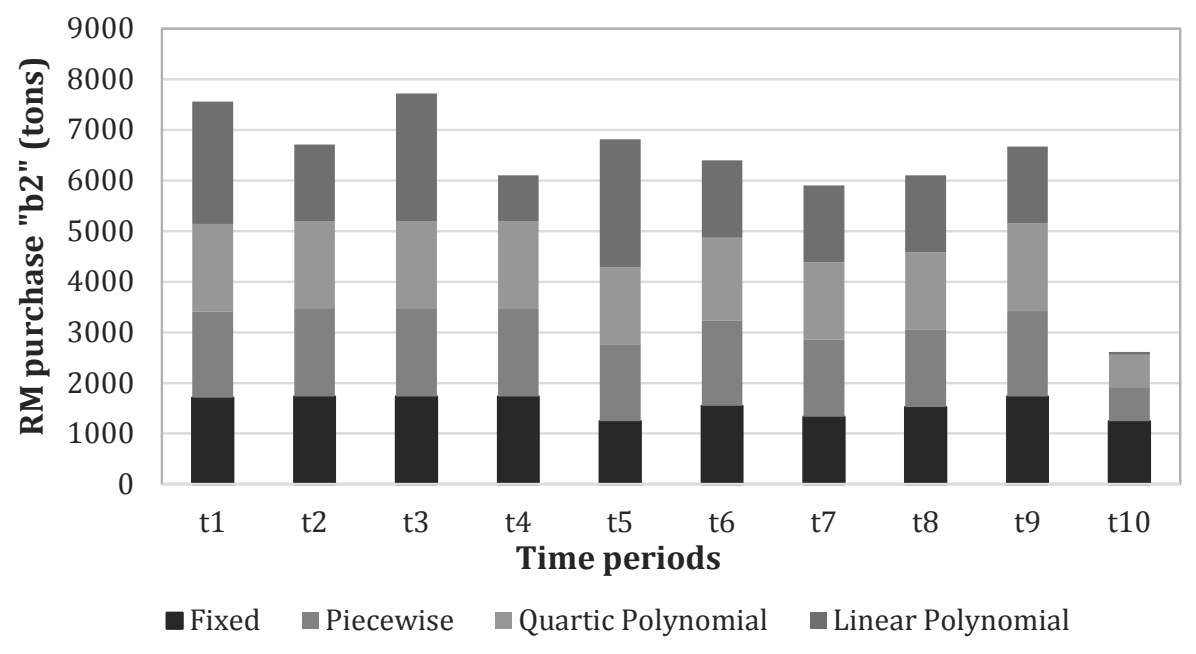

Figure 16- SC2 RM purchase levels

\subsection{Economic assessment}

The decisions obtained according to each pricing model have been used to assess the expected results assuming a perfect information system. To do so, the RM purchase decisions resulting from the different pricing models (as in Figures $9 \& 16$ ) have been allocated to their real prices (Figures $7 \& 8$ ), and the pricing models have been simulated based on the optimal RM purchase decisions and the corresponding real prices. Here it is worth mentioning that the real price policy that the 3rd party will follow according to the quantity demanded by the centralized SC enterprise may have a very complex behavior. Since these real policies may be hard to be integrated in the mathematical model of the centralized SC superstructure, different pricing approximation models are proposed to obtain the optimal quantities to be purchased. In order to compare these approximations, the real total costs (the SC costs considering the original price policy) are computed for the different optimum purchase proposals obtained from each approximation.

Figure 17 and Table 6 illustrate the SC total Cost obtained from the pricing approximation models comparing with the SC real total cost. It can be noticed that the quartic polynomial and the piecewise pricing models lead to the lowest real total costs (M€16.42), while the linear polynomial and the fixed pricing models lead to the highest real total costs; M€16.58 and M€ 16.57. The average fixed pricing model leads to the highest RM purchase cost ( $M € 5.08$ ); $4.3 \%, 6.4 \%$, and $3.5 \%$ comparing with the quartic polynomial, linear polynomial, and piecewise pricing models, respectively, as its decisions do not take into account any price discounts, without allowing any flexibility in the third party decisions. 


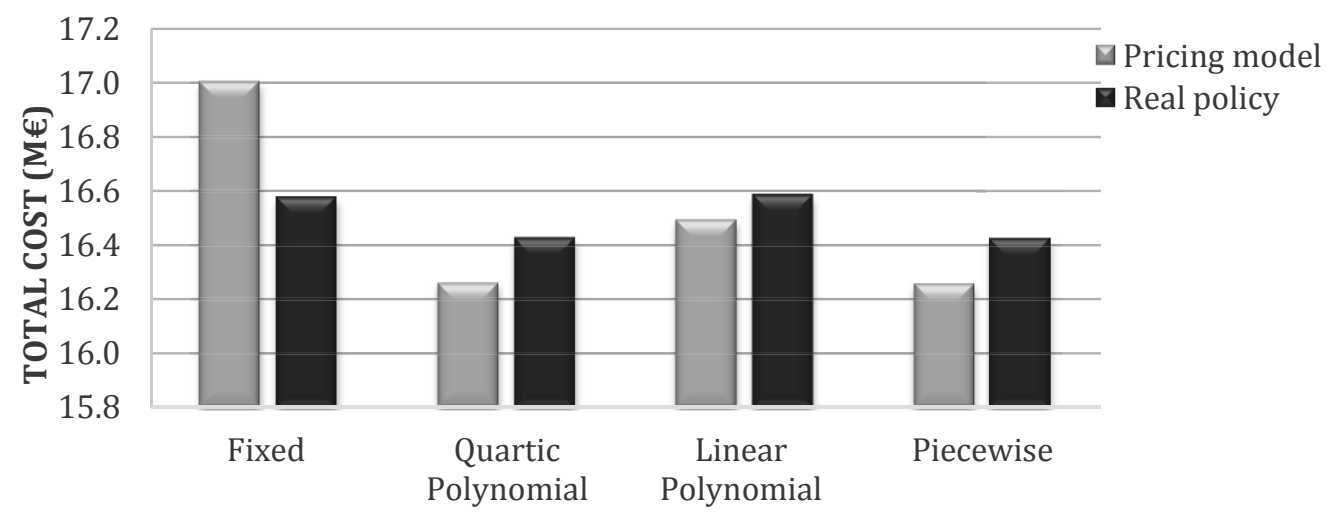

Figure 17- Global SC pricing and real Total Cost

From the models statistics in Table 6, it can be noticed that higher computational effort is needed for solving the piecewise model $(5.8 \mathrm{sec}$ ), comparing with $0.05 \mathrm{CPU}$ sec regarding the fixed pricing model.

Table 6- Global SC models statistics

\begin{tabular}{lccccccc}
\hline & & & & & \multicolumn{2}{c}{ Total Cost (M€) } \\
\hline & Model & $\begin{array}{c}\text { Single } \\
\text { equations }\end{array}$ & $\begin{array}{c}\text { Single } \\
\text { variables }\end{array}$ & $\begin{array}{c}\text { Discrete } \\
\text { variables }\end{array}$ & $\begin{array}{c}\text { CPU } \\
\text { (sec) }\end{array}$ & Pricing & Real \\
\hline Fixed & LP & 2,752 & 4,991 & - & 0.05 & 17.00 & 16.57 \\
\hline $\begin{array}{l}\text { Quartic } \\
\text { Polynomial }\end{array}$ & NLP & 2,952 & 5,191 & - & 0.13 & 16.26 & $\mathbf{1 6 . 4 2}$ \\
\hline $\begin{array}{l}\text { Linear } \\
\text { Polynomial }\end{array}$ & NLP & 2,952 & 5,191 & - & 0.11 & 16.49 & 16.58 \\
\hline Piecewise & MINLP & 3,336 & 5,495 & 240 & 5.80 & 16.26 & $\mathbf{1 6 . 4 2}$ \\
\hline
\end{tabular}

Given that the best pricing approximations need more computing effort than the fixed pricing approach, the question arising here is: Is it possible to find a fixed pricing model that can be used to obtain better solutions than the average fixed pricing approximation? In order to answer this question, different fixed pricing approximation models have been proposed to estimate the real pricing policies. The real pricing patterns were divided into fixed ranges; max (F1), two intermediates (F2 \& F4), min (F5), besides the average fixed model analyzed before (F3). The fixed pricing model has been solved five times (F1-F5), and the optimal RM purchased decisions of each fixed pricing model were used as input for the simulation step (RM purchase decisions vs. real prices), separately.

Table 7 and Figure 18 show the real Total Costs of the global SC resulting from each fixed pricing decisions. The fixed pricing model (F4) leads to the best approximation, with a real total cost (M€ 16.42), which is similar to the results of the piecewise and the quartic polynomial real costs that have been obtained before (Table 6). Unlike what was expected, the average approximation of the real prices (F3) leads to the worst real Total Cost (M€ 16.57).

Table 7- Global SC fixed pricing and real Total Costs

\section{Total cost (M€)}




\begin{tabular}{ccc}
\hline & Pricing & Real \\
\hline F1 & 18.04 & 16.44 \\
F2 & 17.68 & 16.43 \\
F3 & 17.00 & 16.57 \\
F4 & 16.54 & $\mathbf{1 6 . 4 2}$ \\
F5 & 16.09 & 16.47 \\
\hline
\end{tabular}

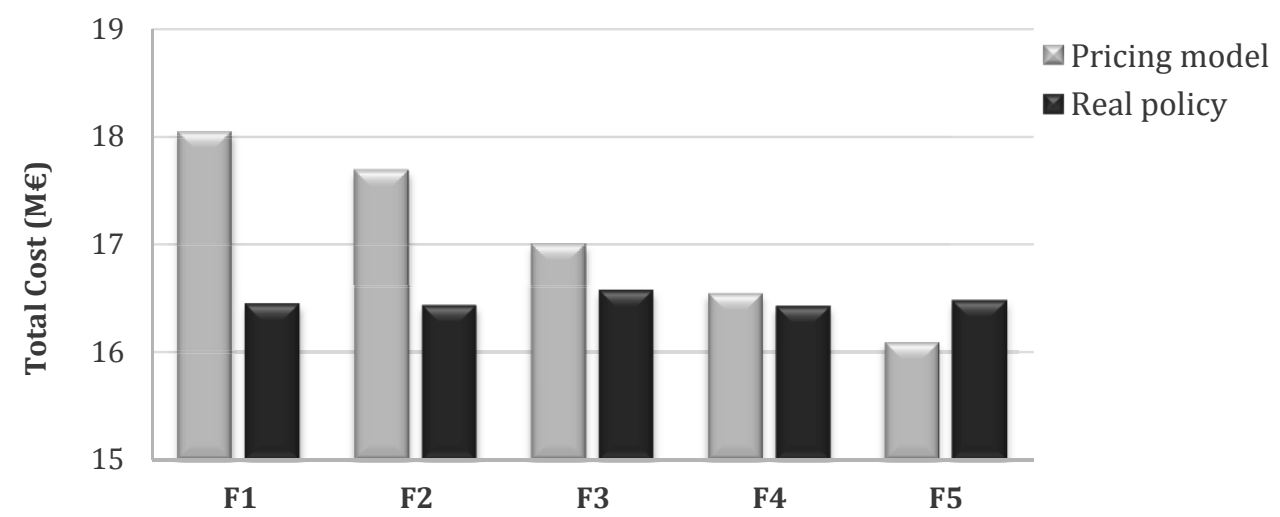

Figure 18- Global SC fixed pricing model vs real Total Costs

\section{Conclusions}

A generic coordinated production- distribution tactical model considering third parties price policies as degree of freedom decisions is developed. Different pricing approximation models (fixed, piecewise, and polynomial) have been proposed for a multi-site multi-echelon multiproduct SC (coordinated and centralized), resulting in several LP, NLP, and MINLP models. The effects of using the different proposed pricing models on the SCs coordination have been verified through a case study that coordinates two main SCs: polystyrene production/distribution SC and its energy generation SC. The results show that different pricing approximations lead to significantly different tactical decisions and economic results. The trend in the piecewise and polynomial models is to purchase higher amounts of RMs in order to get lower prices, taking the advantage of storage in order to store the excess amounts of products for later distribution, resulting in different economic performance. The best pricing approximation model is found to be in favor of the piecewise approach, leading to significant improvements $(4.6 \%$, in the presented case study, in terms of total cost, compared with the average approximation model), although its use requires more computational effort; accordingly, average pricing approximations are not recommended. Flexible pricing approaches within a coordination management give the third parties enough freedom to control their financial flows and thus to compete in the global market management. Furthermore, the generality of the presented tactical based model, derived from considering the echelons SCs as sets in the mathematical formulations and synchronizing the supply and demand of the interacting echelons, gives more flexibility to cope with further supply chain echelons, where each echelon can play different roles: a supplier on one hand and a 
manufacturer on the other hand. In this sense, pricing models can be extended to be used for decentralized SCs as a basis for further price negotiations.

\section{Acknowledgement}

Financial support received from the "Agència de Gestió d'Ajuts Universitaris i de Recerca AGAUR", the Spanish Ministry of Economy and Competitiveness and the European Regional Development Fund, both funding the Project SIGERA (DPI2012-37154-C02-01), and from the Generalitat de Catalunya (2014-SGR-1092-CEPEiMA), is fully appreciated.

$\begin{array}{ll}\text { Acronyms } & \\ \text { CEFIC } & \text { European Chemicals Industry Council } \\ \text { CPU } & \text { Central Processing Unit } \\ \text { DC } & \text { Distribution Center } \\ \text { EPCA } & \text { European Petrochemical Association } \\ \text { GAMS } & \text { The General Algebraic Modeling System } \\ \text { GB } & \text { Gigabyte } \\ \text { GHz } & \text { Gigahertz } \\ \text { LP } & \text { Linear Programming } \\ \text { MIP } & \text { Mixed Integer Programming } \\ \text { MILP } & \text { Mixed Integer Linear Programming } \\ \text { MINLP } & \text { Mixed Integer Non-Linear Programming } \\ \text { NLP } & \text { Non-Linear Programming } \\ \text { PSE } & \text { Process System Engineering } \\ \text { RM } & \text { Raw Material } \\ \text { SC } & \text { Supply Chain } \\ \text { SCM } & \text { Supply Chain Management } \\ \text { SCsCo } & \text { Supply Chains Coordination }\end{array}$

\section{Nomenclature}

\section{Indexes}

E Echelon

$R \quad$ Resource (raw material, product, energy, cash, ...)

$T \quad$ time period

Sets

dc Distribution center

e echelon

$m \quad$ external markets (final consumers)

pl Production plant

$r \quad$ resources (raw materials, products, steam...)

$s \quad$ external suppliers 
time periods

\section{Parameters}

dist $_{r, e}$
dmd $d_{r, e, e^{\prime}, t}$
$P E_{r, e^{\prime}, t, n}$
$\operatorname{prf}_{r, r^{\prime}, e}$
$P R D_{e, t}^{\min }$
$P R D_{e, t}^{\max }$
$P L_{r, e^{\prime}, t, n}$
$Q L_{r, e^{\prime}, t, n}$
$r p_{r, e^{\prime}, t}$
$S T_{e, t}^{\min }$
$S T_{e, t}^{\max }$
ust $_{r, e}$
uprd $_{r, e}$
utr $_{r, e}$
$x_{a, r}$

travel distance of resource $r$ at echelon $e$

external demand of resource $r$ in echelon $e^{\prime}$ (final consumer) at time $t$

price elasticity of demand or resource $r$ in echelon $e^{\prime}$ at time $t$ in price zone $n$

production factor: quantity of resource $r$ required to produce resource $r$ in echelon $e$

minimum production capacity in echelon $e$, time $t$

maximum production capacity of echelon $e$, time $t$

max price at piecewise price zone $n$, time $t$

resource $r$ limit in price zone $n$ at echelon $e$ (external supplier), time $t$

unitary retail price of resource $r$ at echelon $e^{\prime}$ (final consumer), time $t$

minimum storage capacity at echelon $e$, time $t$

maximum storage capacity at echelon $e$, time $t$

Unit storage cost of resource $r$ at echelon $e$

unit production cost of resource $r$ at echelon $e$

unit transport cost of resource $r$ at echelon $e$

Variables:

COST

factor depends on the polynomial grade a of resource $r$

COST

total cost of the centralized SC

$C P R_{e}$

Cost of echelon $e$

$C R M_{e}$

production cost at echelon $e$

$C S T_{e}$

cost of the externally supplied resources at echelon $e$

$C T R_{e}$

storage cost at echelon e

$D_{r, e, e^{\prime}, t}$

transport cost at echelon e

$D m i_{r^{\prime}, e, t}$

amount of resource $r$ delivered from echelon $e$ to echelon $e^{\prime}$ (final market) at time $t$

$P N_{r, e^{\prime}, t, n}$

internal demand of resource $r$, at echelon $e$, time $t$

$P_{r, e^{\prime}, t}$

Elastic price of resource $r$ at echelon $e$ (external supplier) in price zone $n$, time $t$

$\operatorname{prod}_{r, e, t}$

Price of resource $r$ at echelon $e$ (external supplier), time $t$

PROF

$Q E_{r, e^{\prime}, e, t}$

production levels of resource $r$ in echelon $e$, time $t$

$Q_{r, e^{\prime}, t}$ aggregated profit of the global SC network

$Q N_{r, e^{\prime}, t, n}$ resource $r$ from third party echelon $e^{\prime}$ to each echelon $e$, time $t$

$Q R_{r, e, t}$ total resource $r$ from third party e', time $t$

$S T_{r, e, t}$ resource $r$ purchased from $3^{\text {rd }}$ party $\mathrm{e}^{\prime}$ in price zone $n$, time $t$ resource $r$ flows between entities at echelon e, time $t$ Storage levels of resource $r$ at echelon e, time $t$ 
$\mathrm{SALE}_{e} \quad$ economic sales (income) of echelon e

Binary

Variables

$y_{r, e, t, n} \quad$ Binary variable of price piece $n$ of resource $r$ at echelon $e$ (external supplier), time $t$ 